\title{
Disruption of ribosome assembly in yeast blocks cotranscriptional pre-rRNA processing and affects the global hierarchy of ribosome biogenesis
}

\author{
JASON TALKISH, ${ }^{1,2,3,6}$ STEPHANIE BIEDKA, ${ }^{1,2,6}$ JELENA JAKOVLJEVIC, ${ }^{1,2}$ JINGYU ZHANG, ${ }^{1}$ LAN TANG ${ }^{1}$ \\ JOHN R. STRAHLER, ${ }^{4}$ PHILIP C. ANDREWS, ${ }^{4}$ JANINE R. MADDOCK, ${ }^{5}$ and JOHN L. WOOLFORD JR. ${ }^{1,2}$ \\ ${ }^{1}$ Department of Biological Sciences, Carnegie Mellon University, Pittsburgh, Pennsylvania 15213, USA \\ ${ }^{2}$ The Center for Nucleic Acids Science and Technology, Carnegie Mellon University, Pittsburgh, Pennsylvania 15213, USA \\ ${ }^{3}$ Department of Molecular, Cell and Developmental Biology, University of California Santa Cruz, Santa Cruz, California 95064, USA \\ ${ }^{4}$ Department of Biological Chemistry, ${ }^{5}$ Department of Molecular, Cellular, and Developmental Biology, University of Michigan, Ann Arbor, \\ Michigan 48109, USA
}

\begin{abstract}
In higher eukaryotes, pre-rRNA processing occurs almost exclusively post-transcriptionally. This is not the case in rapidly dividing yeast, as the majority of nascent pre-rRNAs are processed cotranscriptionally, with cleavage at the $A_{2}$ site first releasing a pre-40S ribosomal subunit followed by release of a pre-60S ribosomal subunit upon transcription termination. Ribosome assembly is driven in part by hierarchical association of assembly factors and r-proteins. Groups of proteins are thought to associate with pre-ribosomes cotranscriptionally during early assembly steps, whereas others associate later, after transcription is completed. Here we describe a previously uncharacterized phenotype observed upon disruption of ribosome assembly, in which normally late-binding proteins associate earlier, with pre-ribosomes containing 35S pre-rRNA. As previously observed by many other groups, we show that disruption of $60 \mathrm{~S}$ subunit biogenesis results in increased amounts of $35 \mathrm{~S}$ pre-rRNA, suggesting that a greater fraction of pre-rRNAs are processed post-transcriptionally. Surprisingly, we found that early preribosomes containing 35S pre-rRNA also contain proteins previously thought to only associate with pre-ribosomes after early pre-rRNA processing steps have separated maturation of the two subunits. We believe the shift to post-transcriptional processing is ultimately due to decreased cellular division upon disruption of ribosome assembly. When cells are grown under stress or to high density, a greater fraction of pre-rRNAs are processed post-transcriptionally and follow an alternative processing pathway. Together, these results affirm the principle that ribosome assembly occurs through different, parallel assembly pathways and suggest that there is a kinetic foot-race between the formation of protein binding sites and pre-rRNA processing events.
\end{abstract}

Keywords: yeast ribosome assembly; cotranscriptional assembly; pre-rRNA processing; pre-ribosomes; hierarchical assembly

\section{INTRODUCTION}

Eukaryotic ribosome biogenesis is a complex process in which rRNA is coordinately transcribed, folded, modified, processed, and bound by ribosomal proteins ( $\mathrm{r}$-proteins) to produce mature ribosomal subunits. Although these processes occur in a coordinated manner, in vitro reconstitution of bacterial ribosomes has shown that there is an overall hierarchy that governs ribosome assembly (Held et al. 1973; Culver 2003; Talkington et al. 2005; Sykes and Williamson 2009; Woolford and Baserga 2013). Initial folding of rRNA promotes the association of a group of primary binding r-proteins. Biochemical and biophysical approaches have shown

\footnotetext{
${ }^{6}$ These authors contributed equally to this work.

Corresponding author: jw17@andrew.cmu.edu

Article published online ahead of print. Article and publication date are at http://www.rnajournal.org/cgi/doi/10.1261/rna.055780.115.
}

that binding of these r-proteins to rRNA often results in conformational changes within the rRNA that both strengthens the association of the primary binding r-proteins and creates binding sites for the subsequent association of secondary and tertiary binding r-proteins (Held et al. 1973; Nierhaus and Dohme 1974; Talkington et al. 2005; Adilakshmi et al. 2008).

The principles learned about hierarchical assembly in vitro have largely framed the way ribosome assembly is studied in vivo. In addition to the $\mathrm{r}$-proteins, ribosome assembly in vivo is facilitated by more than 200 assembly factors in eukaryotes (Woolford and Baserga 2013). Purification of pre-ribosomal

\footnotetext{
(C) 2016 Talkish et al. This article is distributed exclusively by the RNA Society for the first 12 months after the full-issue publication date (see http://rnajournal.cshlp.org/site/misc/terms.xhtml). After 12 months, it is available under a Creative Commons License (Attribution-NonCommercial 4.0 International), as described at http://creativecommons.org/licenses/ by-nc/4.0/.
} 
intermediates revealed that there is a global hierarchy of association of assembly factors with pre-ribosomes (Nissan et al. 2002). There are assembly factors that associate with pre-ribosomes very early in assembly, those that associate during the middle steps of assembly, those that bind to pre-rRNPs at the end of assembly, and those that are present in particles throughout assembly. This global hierarchy is thought to act as a series of checkpoints during ribosome biogenesis, existing to ensure that ribosome assembly occurs in the proper order, and that late steps of assembly do not occur prematurely (Strunk and Karbstein 2009).

Recently, a number of studies have shown that there is also a hierarchy of association of assembly factors during each step of biogenesis. For example, 14 assembly factors required for 27SB pre-rRNA processing stably associate with pre-ribosomes in a stepwise manner, ultimately leading to the recruitment of the GTPase Nog2 just prior to cleavage of the $\mathrm{C}_{2}$ site (Talkish et al. 2012). More recent work has shown that Nog2 shares a binding site on pre-ribosomes with the nuclear export factor Nmd3. Release of Nog2 allows binding of $\mathrm{Nmd} 3$, enabling pre-ribosomes to transition from the nucleus to the cytoplasm (Matsuo et al. 2014). Thus, the timely association and coordinated release of Nog2 appear to be important regulatory checkpoints in ribosome biogenesis.

Traditionally, ribosome assembly in yeast has been portrayed as beginning with transcription of a 35S pre-rRNA and the formation of a $90 \mathrm{~S}$ pre-ribosome in the nucleolus. The 35S pre-rRNA contains sequences for mature 18S, $5.8 \mathrm{~S}$, and $25 \mathrm{~S}$ rRNAs as well as spacer sequences that are removed through a series of endo- and exonucleolytic cleavages (Fig. 1A, left). Cleavage of $35 \mathrm{~S}$ pre-rRNA at the $\mathrm{A}_{0}, \mathrm{~A}_{1}$, and $\mathrm{A}_{2}$ sites separates the maturation of $43 \mathrm{~S}$ pre-ribosomes from $66 \mathrm{~S}$ pre-ribosomes (Fernandez-Pevida et al. 2014). Although it is thought that the cleavage events that separate maturation of the two particles occur post-transcriptionally in higher eukaryotes, recently it has been shown that in yeast these early pre-rRNA processing steps occur mostly cotranscriptionally (Mougey et al. 1993; Osheim et al. 2004). In rapidly dividing yeast cells, $\sim 70 \%-80 \%$ of pre-rRNA transcripts are cleaved at the $\mathrm{A}_{2}$ site before transcription of the pre-rRNA is completed (Osheim et al. 2004; Kos and Tollervey 2010). Thus, the majority of ribosome assembly is initiated with $43 \mathrm{~S}$ pre-ribosomes that contain $20 \mathrm{~S}$ pre-rRNA and $66 \mathrm{~S}$ pre-ribosomes that contain $27 \mathrm{SA}_{2}$ pre-rRNA (Fig. 1A, right), not with $90 \mathrm{~S}$ pre-ribosomes containing $35 \mathrm{~S}$ pre-rRNA (Fig. 1A, left). In contrast, as cells are grown to stationary phase, a greater fraction of pre-rRNAs are processed post-transcriptionally (Osheim et al. 2004), i.e., a full-length $35 \mathrm{~S}$ pre-rRNA is produced prior to the occurrence of any pre-rRNA processing steps and separation of the two assembling subunits. Therefore, the assembly events leading up to separation of pre-40S and pre-60S particles appear to be regulated by cell growth and proliferation. However, the mechanism by which this regulation occurs, and the downstream effects on ribosome assembly, remain unknown.
Here we describe studies of the assembly factor Drs1 that provide new insights into differences that occur during ribosome biogenesis when early assembly and pre-rRNA processing events occur cotranscriptionally vs. post-transcriptionally. Previously, we showed that the DEAD-box protein (DBP) Drs1 functions in $60 \mathrm{~S}$ ribosomal subunit biogenesis and that missense mutations in Drs1 block 27SB pre-rRNA processing (Ripmaster et al. 1992; Adams et al. 2002). In contrast, here we show that depletion of Drs1 affects earlier steps of pre-rRNA processing, suggesting that Drs1 may function in more than one consecutive step of ribosome assembly. Furthermore, we show that Drs1 interacts with, and is recruited to pre-ribosomes by a subcomplex of assembly factors containing Nop7, Erb1, and Ytm1.

Most importantly, careful examination of the composition of pre-ribosomes upon depletion of Drs1 revealed a phenotype that we believe results from a partial shift from cotranscriptional pre-rRNA processing at the $A_{0}, A_{1}$, and $\mathrm{A}_{2}$ sites to post-transcriptional pre-rRNA processing (Fig. 7, below). We observed that (i) depletion of Drs1 results in a block in 27SA pre-rRNA processing, accompanied later by accumulation of $35 \mathrm{~S}$ pre-rRNAs as cell growth and division slow down. Importantly, although production of $25 \mathrm{~S}$ rRNA is blocked in the absence of Drs1, the post-transcriptionally processed $35 \mathrm{~S}$ pre-rRNA is still competent to produce mature $18 \mathrm{~S}$ rRNA. However, this occurs through a $23 \mathrm{~S}$ pre-rRNA intermediate, produced by direct cleavage of site $A_{3}$, rather than through $20 \mathrm{~S}$ pre-rRNA produced by cleavage at the $\mathrm{A}_{2}$ site (Supplemental Fig. S3). (ii) Disruption of cotranscriptional cleavage of the nascent transcript results in the incorporation of $35 \mathrm{~S}$ pre-rRNA into an early pre-ribosomal intermediate that contains both early- and late-associating assembly factors and r-proteins that do not coexist in the same particles when processing occurs cotranscriptionally. This was most evident by the fact that we see normally late-associating pre-60S subunit assembly factors (Nog2, Arx1, and Lsg1) associating with $35 \mathrm{~S}$ prerRNA. In wild-type conditions, these assembly factors only associate with pre-ribosomes after cleavage at the $\mathrm{A}_{2}$ site has separated maturation of the pre- $40 \mathrm{~S}$ and pre-60S particles (Saveanu et al. 2001; Nissan et al. 2002; Kallstrom et al. 2003; Bradatsch et al. 2007, 2012; Dembowski et al. 2013). Furthermore, mass spectrometric analysis of the Nog2-containing particles from cells depleted of Drs1 revealed the presence of normally late-associating small subunit r-proteins S3 and S20 (Ferreira-Cerca et al. 2007). (iii) Nog2 coimmunoprecipitates components of RNA polymerase I when $35 \mathrm{~S}$ pre-rRNA is produced. This is consistent with the observation that under these conditions Nog2 associates with $35 \mathrm{~S}$ pre-rRNA and suggests that when pre-rRNAs are processed post-transcriptionally, Nog2 associates during transcription. (iv) The shift to post-transcriptional prerRNA processing is likely a result of decreased cellular growth rates upon disruption of ribosome assembly, as we were able to recapitulate the shift to post-transcriptional 
A post-transcriptional pre-rRNA processing 20-30\%

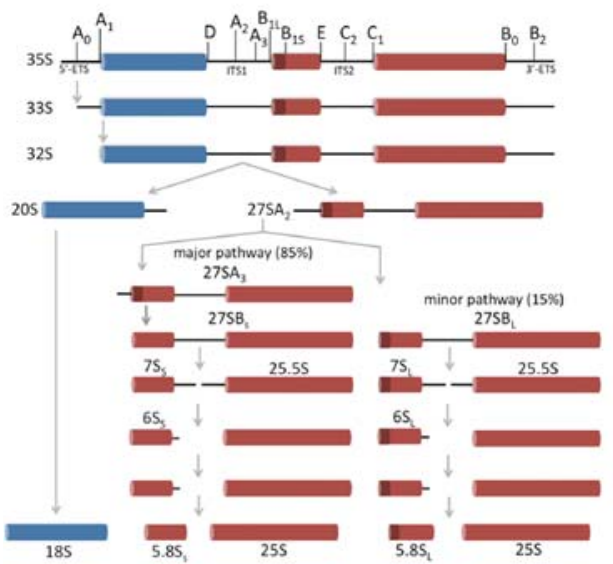

B

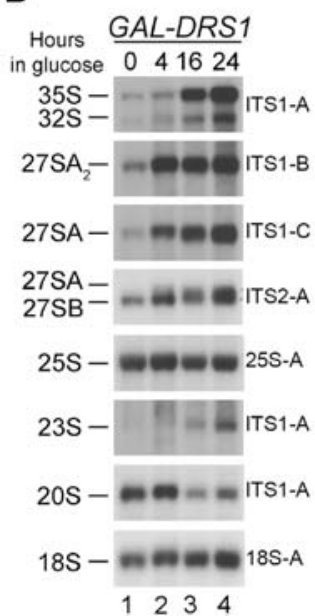

C

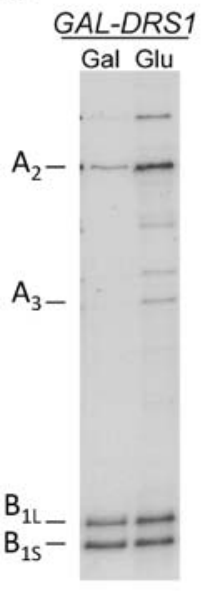

co-transcriptional pre-rRNA processing $70-80 \%$

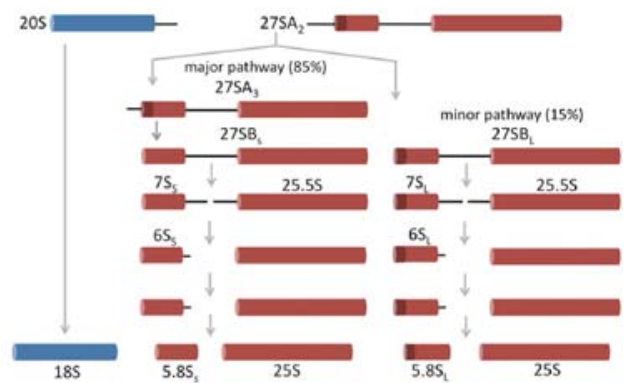

D

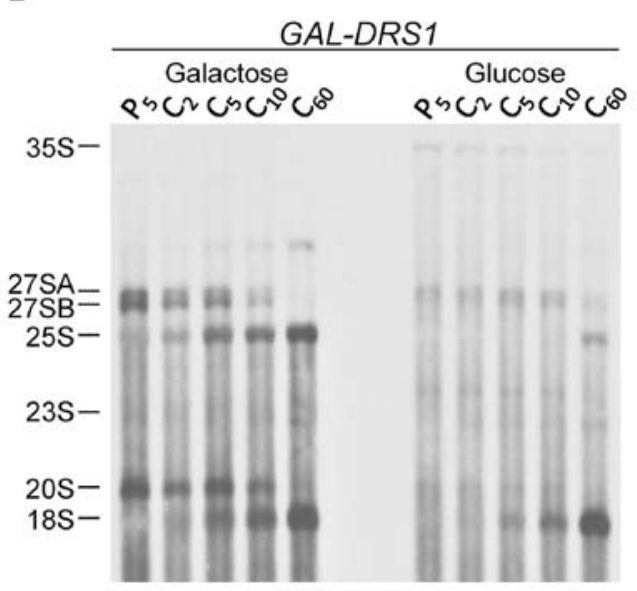

FIGURE 1. Depletion of Drs1 causes accumulation of $27 \mathrm{SA}_{2}$ and $27 \mathrm{SA}_{3}$ pre-rRNAs. (A) The pre-rRNA processing pathway in Saccharomyces cerevisiae. Ribosome assembly in yeast is traditionally portrayed as beginning with transcription of 35S pre-rRNA (left). Because a large fraction of pre-rRNAs are processed cotranscriptionally, ribosome assembly actually initiates more often with $43 \mathrm{~S}$ pre-ribosomes containing $20 \mathrm{~S}$ pre-rRNA and $66 \mathrm{~S}$ pre-ribosomes containing $27 \mathrm{SA}_{2}$ pre-rRNA (right). RNAs of the $40 \mathrm{~S}$ and $60 \mathrm{~S}$ subunits are colored blue and red, respectively. The separately transcribed and processed 5S rRNA is not shown. (B) To assay steady-state levels of pre-rRNAs in the absence of Drs1, the GAL-HA-DRS1 (JWY8637) strain was grown in YEPGal or shifted to YEPGlu media for the indicated time-points. Total RNA was extracted from cells and separated on a $1.2 \%$ agarose- $6 \%$ formaldehyde gel. Pre-rRNAs were assayed by Northern blotting. Oligonucleotide probes used are indicated on the right. Gel lanes are numbered. Quantification of triplicates of this experiment is shown in Supplemental Figure S2. (C) The steady-state levels of the $5^{\prime}$ ends of $27 \mathrm{~S}$ pre-rRNAs were assayed by primer extension using an oligonucleotide probe complementary to ITS2 (de la Cruz et al. 1998). RNA was extracted from the GAL-HA-DRS1 strain grown in YEPGal or shifted to YEPGlu for $16 \mathrm{~h} . \mathrm{B}_{1 \mathrm{~L}}$ and $\mathrm{B}_{1 \mathrm{~S}}$ represent the $5^{\prime}$ end of $27 \mathrm{SB}_{\mathrm{L}}+7 \mathrm{~S}_{\mathrm{L}}$ and $27 \mathrm{SB}_{\mathrm{S}}+7 \mathrm{~S}_{\mathrm{S}}$ pre-rRNAs, respectively. $(D)$ To assay synthesis and turnover of pre-rRNA intermediates in the absence of Drs1, the GAL-HADRS1 strain was grown in C-met + Gal or shifted to C-met + Glu for $16 \mathrm{~h}$. Cells were pulse labeled with $\left[{ }^{3} \mathrm{H}\right.$ methyl]-methionine for 5 min and chased with a molar excess of unlabeled methionine for 2, 5, 10, and $60 \mathrm{~min}$. Total RNA was extracted and separated on a $1.2 \%$ agarose- $6 \%$ formaldehyde gel.

pre-rRNA processing by growing cells to high density or under various stressful conditions.

Together, these data show that the neighborhoods or binding sites of late-associating assembly factors have the potential to also form very early in ribosome biogenesis, before pre-rRNA processing removes spacer sequences. This suggests that during the normal course of ribosome biosynthesis, there is a kinetic foot-race between the formation of protein binding sites and the removal of pre-rRNA spacers.

\section{RESULTS}

\section{Disruption of pre-60S ribosomal subunit assembly events leads to post-transcriptional pre-rRNA processing}

We previously showed that cold-sensitive $d r s 1$ missense mutants are defective in 60S ribosomal subunit assembly due to a block in 27SB pre-rRNA processing (Ripmaster et al. 1992). However, a number of pieces of evidence suggest that Drs1 
also functions in preceding steps of 60S subunit assembly together with the well-characterized Nop7 subcomplex: (i) Mutations in NOP7 are synthetically lethal with drs1 mutations, in an allele-specific manner (Adams et al. 2002). (ii) Overexpression of DRS1 can suppress temperature-sensitive growth defects of nop7 mutants, which are blocked at an earlier step of assembly than the $d r s 1$ missense mutants (Supplemental Fig. S1A). (iii) Drs1 can be purified with the Nop7-subcomplex upon turning off transcription of rRNA and disrupting assembly of ribosomes (Merl et al. 2010). (iv) Consistent with this observation, Drs1 is part of a saltstable Nop7-subcomplex (Supplemental Fig. S1B). (v) Drs1 is dependent upon Nop7 to associate with pre-ribosomes, although Nop7 is not dependent on Drs1 (Supplemental Fig. S1C,D). (vi) Drs1 can bind the Nop7-subcomplex in vitro (Supplemental Fig. S1E).

To further investigate the earlier function of Drs1, we assayed effects on pre-rRNA processing upon depletion of Drs1, using a GAL-DRS1 strain. Upon shifting cells to glucose-containing medium to deplete Drs1, we observed a strong accumulation of $27 \mathrm{SA}_{2}$ and $27 \mathrm{SA}_{3}$ pre-rRNAs, relative to $27 \mathrm{SB}$ pre-rRNA (Fig. 1B,C). The accumulation of $27 \mathrm{SA}$ pre-rRNA was evident as early as $4 \mathrm{~h}$ after the shift (Fig. 1B, lane 2), even though cells were still growing at wild-type rates (data not shown). As seen upon depletion of other pre-60S subunit assembly factors, we also observed accumulation of $35 \mathrm{~S}$ and $33 \mathrm{~S} / 32 \mathrm{~S}$ pre-rRNAs at later time-points, suggesting that a greater fraction of pre-rRNAs are processed post-transcriptionally under these conditions (Sun and Woolford 1994; Zanchin et al. 1997; de la Cruz et al. 1998, 2005; Kressler et al. 1998, 1999; Zanchin and Goldfarb 1999; Burger et al. 2000; Dunbar et al. 2000; Basu et al. 2001; Daugeron et al. 2001; Pestov et al. 2001; Saveanu et al. 2001, 2003, 2007; Adams et al. 2002; Oeffinger et al. 2002; Wehner and Baserga 2002; Oeffinger and Tollervey 2003; Dez et al. 2004; Emery et al. 2004; Galani et al. 2004; Horsey et al. 2004; Rodriguez-Mateos et al. 2009). Furthermore, this was accompanied by a decrease in levels of $20 \mathrm{~S}$ prerRNA and increased amounts of $23 \mathrm{~S}$ pre-rRNA (Fig. 1B, lanes 3 and 4, and Supplemental Fig. S2). Pulse-chase analysis revealed that pre-rRNAs destined for the $60 \mathrm{~S}$ subunit were largely unstable and turned over; however, the $35 \mathrm{~S}$ prerRNA that accumulated upon Drs1 depletion could be processed to $18 \mathrm{~S}$ rRNA, albeit not through the $20 \mathrm{~S}$ intermediate (Fig. 1D). This suggests that $35 \mathrm{~S}$ pre-rRNA can undergo direct cleavage at the $\mathrm{A}_{3}$ site to produce $23 \mathrm{~S}$ and $27 \mathrm{SA}_{3}$ pre-rRNA, and that the $23 \mathrm{~S}$ pre-rRNA is competent to undergo processing to form mature 18S rRNA (Supplemental Fig. S3, bottom).

Together, these results reveal that, like depletion of Nop7 (Adams et al. 2002), depletion of Drs1 blocks $27 \mathrm{SA}_{2}$ and $27 \mathrm{SA}_{3}$ pre-rRNA processing. Most importantly, the accumulation of $35 \mathrm{~S}$ and $23 \mathrm{~S}$ pre-rRNAs at late time-points suggests a partial shift from co- to post-transcriptional pre-rRNA processing.

\section{Nop7-containing pre-ribosomes are enriched for early-associating assembly factors, but also late-associating small subunit r-proteins, upon a shift to post-transcriptional pre-rRNA processing}

To more thoroughly understand the relationship between Drs1 and other proteins required for $27 \mathrm{SA}_{3}$ pre-rRNA processing, we investigated how the composition of $66 \mathrm{~S}$ pre-ribosomes changes in the absence of Drs1, using a combination of semiquantitative iTRAQ mass spectrometry and Western blotting. Upon depletion of Drs 1 and purification of pre-ribosomes using Nop7-TAP, we observed a number of expected changes in pre-ribosome composition compared to wildtype cells. Consistent with an early block in $60 \mathrm{~S}$ subunit assembly, we observed accumulation of pre-60S subunit assembly factors known to associate with pre-ribosomes early in assembly (Fig. 2A,D; Dbp2, Pwp1, Mak5, Nop4, Rrp5, Mak11, Rrp15, etc.) and diminished amounts of assembly factors and r-proteins only thought to stably associate after $27 \mathrm{SA}_{3}$ pre-rRNA processing (Fig. 2A,C,D; Nsa2, Nog2, Arx1, Rsa4, Nop3, Ipi1, Rix1, Ipi3; Nissan et al. 2002). This phenotype is often observed upon blocking early steps in $60 \mathrm{~S}$ subunit biogenesis (Lebreton et al. 2008; Sahasranaman et al. 2011; Jakovljevic et al. 2012; Shimoji et al. 2012; Dembowski et al. 2013; Gamalinda et al. 2014). Furthermore, Nop7 copurified increased amounts of $35 \mathrm{~S}$ pre-rRNA, consistent with the accumulation of early-associating assembly factors and a shift to a greater amount of post-transcriptional pre-rRNA processing than in wild-type cells (Supplemental Fig. S4A).

Unexpectedly, we also observed copurification of increased levels of small subunit r-proteins and pre-40S subunit assembly factors upon depletion of Drs1 (Fig. 2B,C). Of the small subunit $\mathrm{r}$-proteins that were enriched in Nop7-TAP particles, those most enriched were proteins that bind the $3^{\prime}$ domain of $18 \mathrm{~S}$ rRNA and whose bacterial homologs have been shown to be late, tertiary binders (S20 and S3) (Fig. 2E; Mulder et al. 2010; Karbstein 2011). Since early steps of pre-rRNA processing occur cotranscriptionally in rapidly growing wild-type yeast (Osheim et al. 2004; Kos and Tollervey 2010), r-proteins S3 and S20 are thought to stably associate with the assembling $40 \mathrm{~S}$ subunit only after release of the nascent $43 \mathrm{~S}$ pre-ribosome by cleavage at the $\mathrm{A}_{2}$ site (Mulder et al. 2010; Strunk et al. 2011). Nop7, on the other hand, assembles into pre-ribosomes prior to $\mathrm{A}_{2}$ cleavage, and after cleavage travels with the $66 \mathrm{~S}$ pre-ribosome. Thus, Nop7 is not predicted to be in the same pre-ribosomal particles with r-proteins S3 and S20 when pre-rRNAs are processed cotranscriptionally. The fact that we see significant enrichment of S3 and S20 in Nop7-TAP particles from cells depleted of Drs1 suggests that there is decreased cotranscriptional separation of the assembling pre- $40 \mathrm{~S}$ and pre-60S subunits. This is consistent with the observed accumulation of $35 \mathrm{~S}$ pre-rRNA in the absence of Drs1 (Fig. 1B), and likely reflects a shift from cotranscriptional to more post-transcriptional pre-rRNA processing. 
A
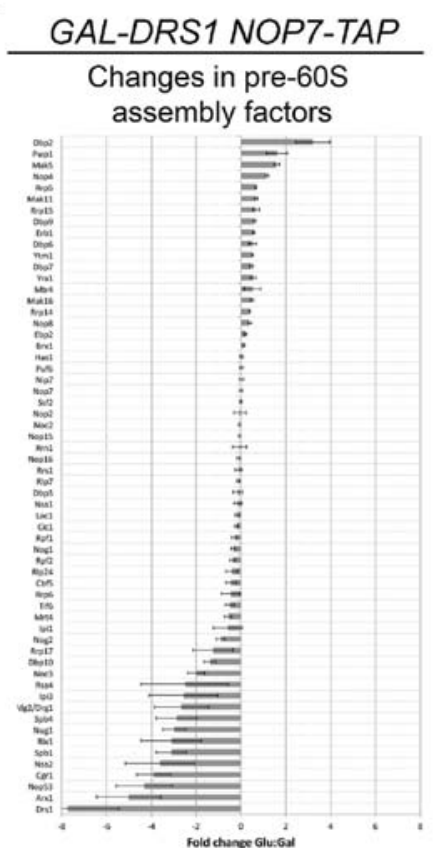

B
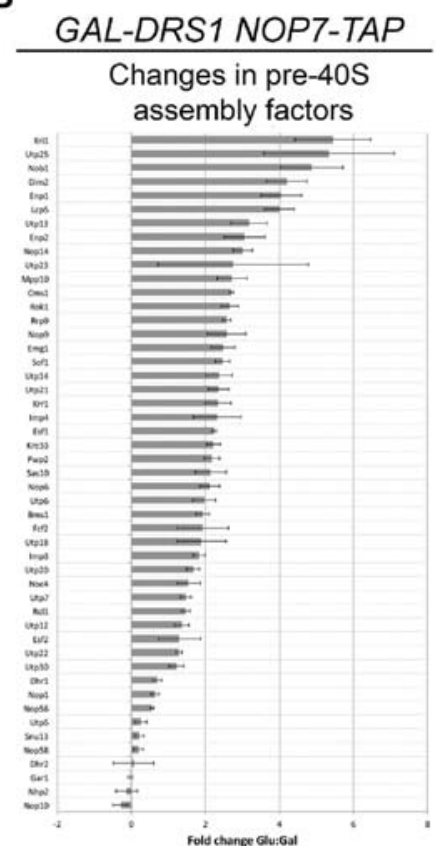

C

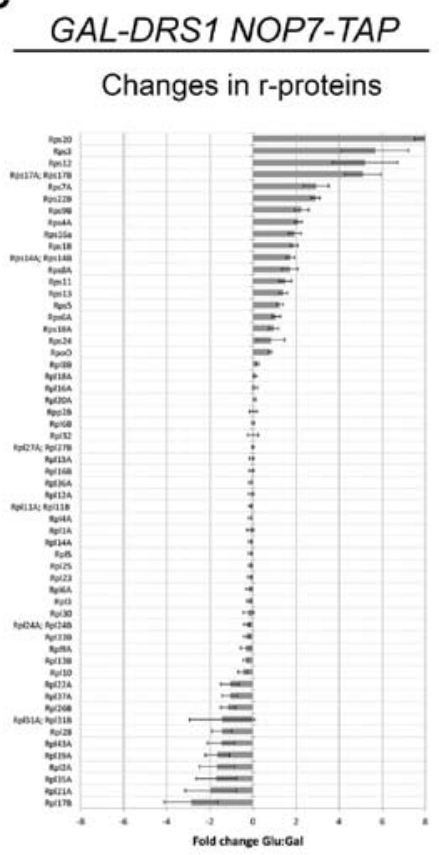

D

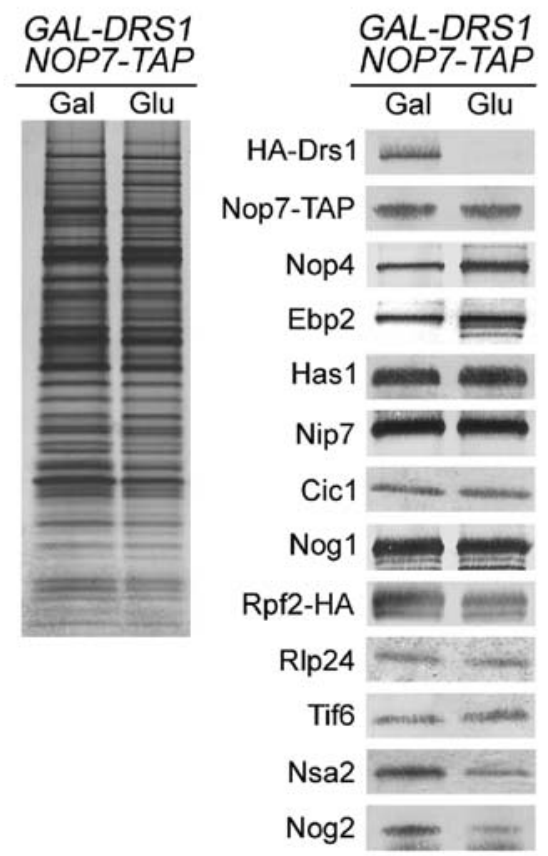

E
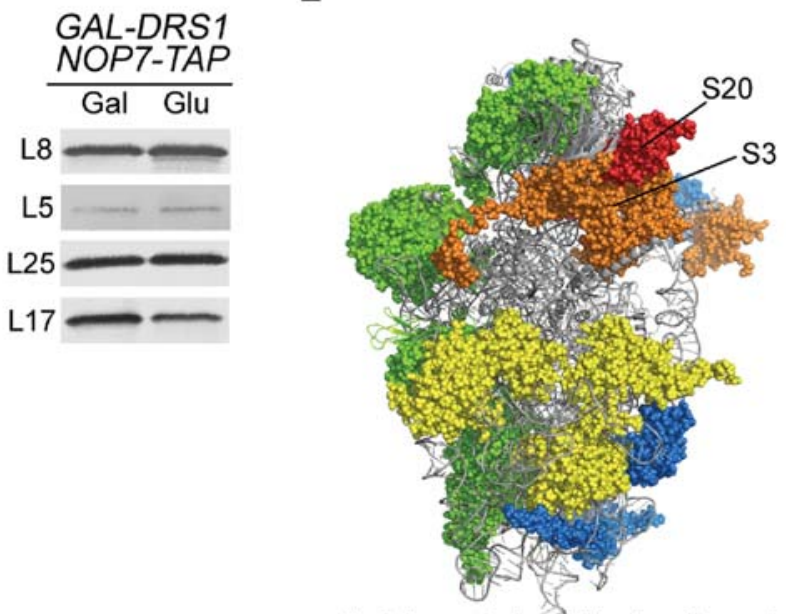

Enrichment of small subunit r-proteins

$<1$ fold

1-2 fold

2-4 fold

4-6 fold

$>6$ fold

FIGURE 2. In the absence of Drs1, pre-ribosomes are enriched for early assembly factors and contain diminished amounts of late assembly factors. $(A-C)$ Pre-ribosomes were affinity purified from the GAL-HA-DRS1 NOP7-TAP strain (JWY8636) grown in YEPGal or shifted to YEPGlu for $16 \mathrm{~h}$ to deplete Drs1. Purified pre-ribosomes were assayed by semiquantitative iTRAQ mass spectrometry to identify pre-60S subunit assembly factors $(A)$, pre-40S subunit assembly factors and SSU components $(B)$, and ribosomal proteins $(C)$, and to compare relative amounts of each in wild-type and Drs1-depleted cells. Each data point shows the fold change of the respective protein upon depletion of Drs1. Error bars indicate the SEM. $(D)$ To confirm iTRAQ results, pre-ribosomes were purified, separated by SDS-PAGE, and visualized by silver staining. Western blots were performed against indicated proteins. (E) The crystal structure of the yeast 40S ribosomal subunit (PDB 4V88). R-proteins that are enriched in Nop7-TAP containing preribosomes are highlighted. Colors indicate the fold-change observed for each r-protein. R-proteins S3 and S20 are most enriched upon Drs 1 depletion and are indicated. 


\section{Upon disruption of cotranscriptional pre-rRNA processing, early $66 \mathrm{~S}$ pre-ribosomes are enriched for the late-associating assembly factor Nog2}

The results above suggest that, upon disruption of $60 \mathrm{~S}$ subunit biogenesis, a greater fraction of pre-rRNAs are processed post-transcriptionally, resulting in the formation of an early pre-ribosome containing $35 \mathrm{~S}$ pre-rRNA, associated with r-proteins (S3 and S20) that normally bind to $20 \mathrm{~S}$ prerRNA after cleavage of the $\mathrm{A}_{2}$ site. This suggests that the binding sites for S3 and S20 have the potential to form prior to any pre-rRNA processing steps.

To further investigate the nature of early pre-ribosomes accumulating in the absence of Drs1, we epitope-tagged the assembly factor Ssf1 to purify pre-ribosomes upon Drs1 depletion. In contrast to Nop7, which purifies a wide range of assembly intermediates, Ssf1 associates with nascent particles early in assembly and dissociates from pre-ribosomes during the lifetime of 27SB pre-rRNA, before Nog2 joins pre-ribosomes (Fatica et al. 2002). We reasoned that by using an assembly factor bound to a much narrower subset of early intermediates than those containing Nop7, we could minimize the effect of changing the relative distribution of purified particles upon depletion of Drs1, and therefore better interpret changes in pre-ribosome composition.

We were surprised to find that when Drs1 is depleted, Ssf1-TAP pre-ribosomes coimmunoprecipitate Nog2 (Supplemental Fig. S4B). Although both Ssf1 and Nog2 copurify 27SB pre-rRNA, a number of studies have convincingly shown that in wild-type cells Ssf1 dissociates from pre-ribosomes prior to Nog2 binding, and therefore these two proteins are present in mutually exclusive populations of pre-ribosomes (Saveanu et al. 2001; Fatica et al. 2002; Kressler et al. 2008; Matsuo et al. 2014). How do we reconcile this observation with our finding that decreased amounts of Nog2 associate with Nop7-containing pre-ribosomes when Drs1 is depleted? This is likely due to changes in the relative distribution of Nop7-containing particles in wild-type vs. mutant conditions. In wild-type cells, the longest-lived Nop7-associated intermediates are particles containing 27SB pre-rRNA, a significant amount of which are also bound by Nog2. In the absence of Drs1, assembly is blocked prior to the formation of 27SB particles, likely accounting for the observed relative decrease of Nog2 in Nop7-TAP particles (Fig. 2A,D).

The fact that we could detect Nog2 copurifying with proteins that normally dissociate from pre-ribosomes before Nog2 binds suggests that even though depletion of Drs1 blocks early steps of pre-60S subunit biogenesis, assembly factors that normally bind after processing of $27 \mathrm{SA}_{3}$ prerRNA can now associate with earlier pre-ribosomes.

Late-associating and early-associating pre-60S subunit assembly factors are in the same pre-ribosomal particles when pre-rRNAs are processed post-transcriptionally

The data above suggest that in the absence of Drs1, pre-ribosomes contain both late pre-40S subunit r-proteins (S3 and
S20) and late pre-60S subunit assembly factors (Nog2). To further investigate this idea, we tested whether other late-associating pre-60S subunit assembly factors might behave similarly to Nog2 and r-proteins S3 and S20. If depletion of Drs1 affects cotranscriptional cleavage of the $\mathrm{A}_{2}$ site, we might predict that not only Nog2, but also other late-associating pre-60S subunit assembly factors would copurify with assembly factors that normally dissociate from pre-ribosomes early. To test this prediction, we TAP-tagged Nog2, Arx1, and Lsg1 in the GAL-HA$D R S 1$ strain. Arx1, like Nog2, is primarily a nucleoplasmic assembly factor, thought to associate with $66 \mathrm{~S}$ pre-ribosomes only after 27SB pre-rRNA is generated (Saveanu et al. 2001; Nissan et al. 2002; Bradatsch et al. 2007, 2012). Lsg1 associates with 66S pre-ribosomes in the cytoplasm (Nissan et al. 2002; Kallstrom et al. 2003). We used each of these TAP-tagged assembly factors to purify pre-ribosomes from wild-type cells and cells in which Drs1 was depleted for $16 \mathrm{~h}$. As shown in Figure 3D (lanes 1, 3, and 5), pre-ribosomes purified using these late factors from wild-type cells are fairly simple particles, primarily composed of r-proteins and several assembly factors. However, when Drs1 was depleted, we saw that Nog2-, Arx1-, and Lsg1-TAP purified more complex particles, enriched for high-molecular weight assembly factors (Fig. 3D, lanes 2, 4, and 6). In wild-type cells, many of these high-molecular weight proteins (Rrp5, Rrp12, Noc1/Mak21, Erb1, Nop4, etc.) assemble and dissociate early from pre-ribosomes, before or immediately after these late TAP-tagged proteins join the nascent particle (Nissan et al. 2002; Horsey et al. 2004; Zhang et al. 2007; Matsuo et al. 2014). Thus, the fact that late factors Nog2, Arx1, and Lsg1 copurify early pre-ribosomal proteins when Drs 1 is depleted is consistent with our results of late-associating Nog2 being present in early Ssf1-TAP containing pre-ribosomes upon depletion of Drs1 (Supplemental Fig. S4B).

To investigate in more detail the changes in Nog2-containing pre-ribosomes upon depletion of Drs1, we used iTRAQ mass spectrometry and Western blotting (Fig. 3A-C,E). We found that many pre-60S subunit assembly factors were enriched in Nog2-containing particles when Drs1 was depleted, especially early assembly factors such as Ssf1, Npa1, and Rrp5, all of which have been reported to dissociate from pre-ribosomes before 27SB pre-rRNA is generated and before Nog2 binds pre-ribosomes in wild-type cells (Fig. 3A,D,E; Fatica et al. 2002; Nissan et al. 2002; Dez et al. 2004; Hierlmeier et al. 2012).

Even more striking, we observed substantial enrichment of small subunit r-proteins as well as pre-40S subunit assembly factors (Fig. 3B,C). Similar to our results with Nop7-TAP (Fig. 2), we see that Nog2-TAP pre-ribosomes purified from Drs1-depleted cells are highly enriched for the late-associating r-proteins S3 and S20 (Fig. 3C).

\section{Late-associating pre-60S subunit assembly factors coimmunoprecipitate early pre-rRNAs upon disruption of cotranscriptional pre-rRNA processing}

Thus far, our results have demonstrated that depletion of Drs 1 results in decreased cotranscriptional cleavage of the $A_{0}, A_{1}$, 
A

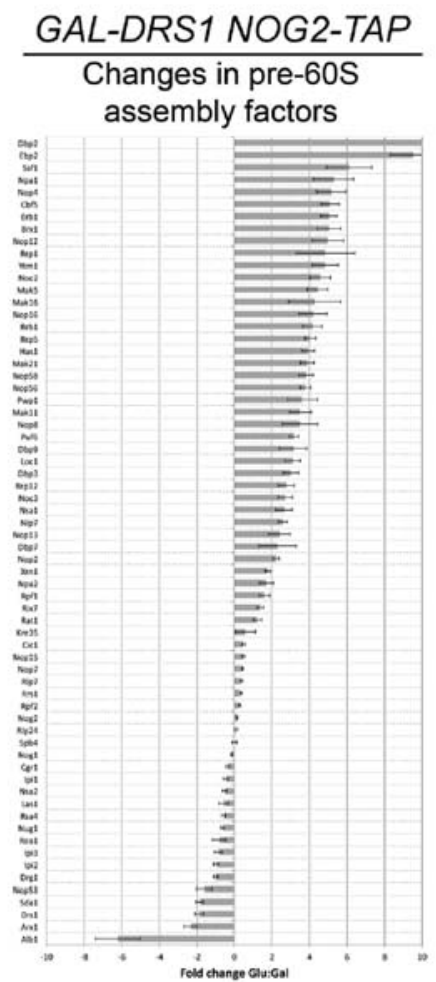

B

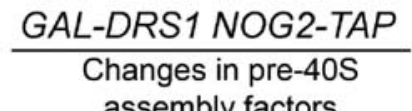
assembly factors

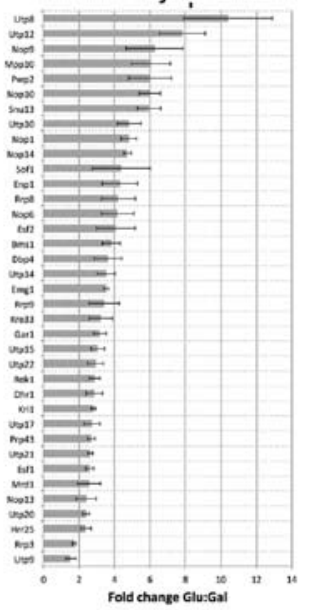

C

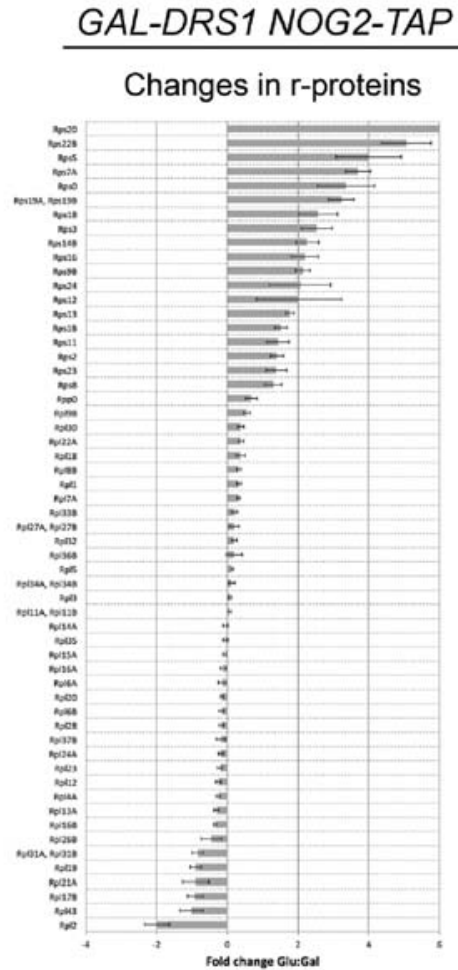

D

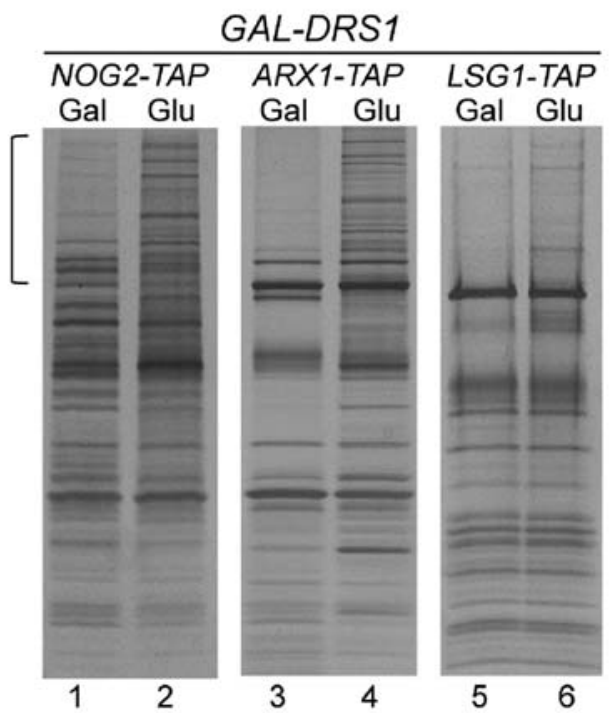

E

GAL-DRS1 NOG2-TAP

\begin{tabular}{|c|c|c|}
\hline & Gal & Glu \\
\hline HA-Drs1 & & \\
\hline Nog2-TAP & $=$ & $=$ \\
\hline Ssf1-HA & & - \\
\hline Nop4 & & $\longrightarrow$ \\
\hline $\mathrm{Brx} 1-\mathrm{HA}$ & $-\infty$ & mine \\
\hline Ebp2 & & $E$ \\
\hline Rrp5-HA & - & - \\
\hline Has1 & was & $E$ \\
\hline Mak11-HA & & hisice \\
\hline Rrp12-HA & Ewise & man \\
\hline Nip7 & & $\dot{-}$ \\
\hline
\end{tabular}

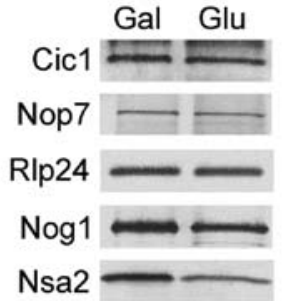

Nsa2

FIGURE 3. Late-associating and early-associating pre-60S subunit assembly factors are in the same pre-ribosomal particles when pre-rRNAs are processed post-transcriptionally. $(A-C)$ Pre-ribosomes were affinity-purified from the GAL-HA-DRS1 NOG2-TAP strain (JWY8695) grown in YEPGal or shifted to YEPGlu for $16 \mathrm{~h}$ to deplete Drs1. Purified pre-ribosomes were assayed by iTRAQ mass spectrometry as described in Figure 2A. Shown is the fold change in pre-60S subunit assembly factors $(A)$, pre- 40 S subunit assembly factors $(B)$, and ribosomal proteins $(C)$. Error bars indicate the SEM. (D) Pre-ribosomes were affinity-purified from the GAL-HA-DRS1 strain grown in YEPGal or shifted to YEPGlu using Nog2-TAP (JWY8695), Arx1-TAP (JWY8481), or Lsg1-TAP (JWY8915). Purified pre-ribosomes were separated by SDS-PAGE and visualized by silver staining. The bracket indicates the enrichment of high molecular weight assembly factors upon depletion of Drs1 that are known to be present in early 66S pre-ribosomes, but absent in late pre-ribosomes. (E) Western blotting was performed to confirm the GAL-HA-DRS1 NOG2-TAP iTRAQ data.

and $\mathrm{A}_{2}$ sites (i.e., increased levels of $35 \mathrm{~S}$ pre-rRNA, Fig. 1B,D) and in the formation of pre-ribosomes containing both pre$40 \mathrm{~S}$ and pre-60S subunit assembly factors thought to only associate with pre-ribosomes after $\mathrm{A}_{2}$ cleavage has occurred (Fig. 3). Therefore, we would expect that these normally late-associating factors would now be associated with 
$35 \mathrm{~S}$ pre-rRNA. To test this prediction, we purified pre-ribosomes from wild-type and Drs1-depleted cells using Nog2-, Arx1-, and Lsg1-TAP, and then assayed by primer extension which pre-rRNAs copurified with each assembly factor. As negative controls, we assayed pre-rRNAs that copurified with Nob1-TAP or that bound to IgG-coated beads using an extract from an untagged parent strain. Nob1 primarily associates with $43 \mathrm{~S}$ pre-ribosomes containing $20 \mathrm{~S}$ pre-rRNA, i.e., after $A_{0}, A_{1}$, and $A_{2}$ cleavage (Fatica et al. 2003; Schafer et al. 2003; Dembowski et al. 2013). Thus, we consider the signal observed for $35 \mathrm{~S}$ pre-rRNA coimmunoprecipitated with Nob1-TAP from wild-type cells to be background amounts (Fig. 4A; lane 7). Nog2-TAP and Arx1-TAP coimmunoprecipitated $27 \mathrm{SB}$ pre-rRNA, but not $35 \mathrm{~S}, 27 \mathrm{SA}_{2}$, and $27 \mathrm{SA}_{3}$ prerRNAs from wild-type cell extracts, while Lsg1-TAP did not coimmunoprecipitate either $35 \mathrm{~S}$ or $27 \mathrm{~S}$ pre-rRNAs (Fig. 4A, lanes 1, 3, and 5). Interestingly, upon depletion of Drs1, we observed that Nog2-, Arx1-, and Lsg1-TAP coimmunoprecipitated above-background amounts of $35 \mathrm{~S}, 27 \mathrm{SA}_{2}$, and $27 \mathrm{SA}_{3}$ pre-rRNAs (Fig. 4A, lanes 2, 4, and 6). Consistent with an early block in 27SA pre-rRNA processing, we see that Nog2-TAP and Arx1-TAP coimmunoprecipitated decreased amounts of 27SB pre-rRNA relative to 27SA pre-rRNA (Fig. 4A, lanes 2 and 4).

Thus, depletion of Drs1 results in decreased cotranscriptional cleavage at the $A_{0}, A_{1}$, and $A_{2}$ sites. When this occurs, normally late-assembling Nog2, Arx1, and Lsg1 associate with a very different population of pre-ribosomal particles that contain 35 S pre-rRNA (Fig. 4B).

\section{Nog2-containing pre-ribosomes are enriched with RNA polymerase I components upon depletion of Drs1}

Recently, a number of ribosome assembly factors were shown to copurify with RNA polymerase I (Pol I), suggesting that they are recruited to pre-ribosomes cotranscriptionally (Hierlmeier et al. 2012). Many of these factors, including Drs1 and Nop7, are proteins that associate with pre-ribosomes early in ribosome biogenesis. Late-associating proteins, such as Nog2, were not identified in a complex with Pol I, consistent with their binding pre-ribosomes after completion of transcription. In the course of our mass spectrometric analysis of pre-ribosomes isolated from cells when Drs1 is depleted, we identified subunits specific to Pol I (Rpa49 and Rpa135), but not Pol II or Pol III. When Drs1 was depleted and pre-ribosomes were purified using Nop7TAP, no enrichment of Rpa49 and Rpa135 was seen (Fig. $5)$. Interestingly, when pre-ribosomes were purified from Drs1-depleted cells using Nog2-TAP, Rpa49 and Rpa135 were enriched $\sim 4.5$-fold and $\sim 3.5$-fold, respectively (Fig. 5 ), suggesting that Nog2 is now binding to nascent prerRNA cotranscriptionally.

In wild-type cells, Nop7 copurifies with Pol I, indicating it normally associates with pre-ribosomes cotranscriptionally (Hierlmeier et al. 2012). Thus, even upon a shift from co-
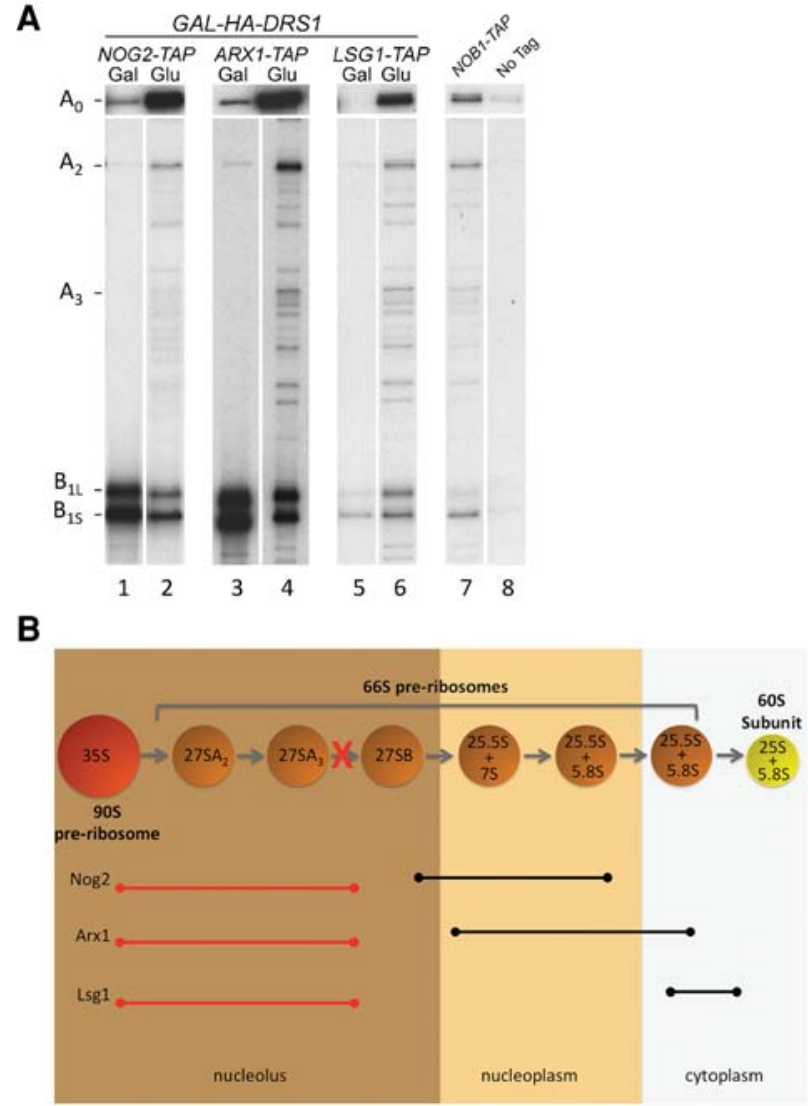

FIGURE 4. In the absence of Drs1, late-associating assembly factors copurify early pre-rRNA intermediates. (A) Pre-ribosomes were affinity-purified using Nog2-TAP (JWY8695), Arx1-TAP (JWY8481), or Lsg1-TAP (JWY8915), from the GAL-HA-DRS1 strain grown in YEPGal or shifted to YEPGlu for $16 \mathrm{~h}$ to deplete Drs1. RNA was extracted from purified pre-ribosomes and pre-rRNAs were detected by primer extension. An oligonucleotide complementary to the $5^{\prime}$-ETS was used to detect the $5^{\prime}$ end of $35 \mathrm{~S}$ pre-rRNA $\left(\mathrm{A}_{0}\right)$ and an oligonucleotide complementary to ITS2 was used to detect the $5^{\prime}$ ends of $27 \mathrm{~S}$ pre-rRNAs $\left(\mathrm{A}_{2}\right.$, $\left.A_{3}\right) . B_{1 L}$ and $B_{1 S}$ represent the $5^{\prime}$ end of $27 \mathrm{SB}_{\mathrm{L}}+7 \mathrm{~S}_{\mathrm{L}}$ and $27 \mathrm{SB}_{\mathrm{S}}+7 \mathrm{~S}_{\mathrm{S}}$ pre-rRNAs, respectively. Nob1-TAP (JWY7769) and the untagged parent strain (JWY8894) serve as negative controls. (B) Model describing the timing of association of Nog2, Arx1, and Lsg1 in wild-type and Drs1-depleted cells blocked at $27 \mathrm{SA}_{3}$ pre-rRNA processing. Spheres represent consecutive pre-ribosome intermediates. Black lines indicate the pre-rRNAs associated with each assembly factor in wild-type cells. Red lines indicate the pre-rRNAs associated with each assembly factor in the absence of Drs1.

to more post-transcriptional pre-rRNA processing, Nop7 still associates with pre-rRNAs cotranscriptionally. Furthermore, Pol I components are not enriched in Nop7 particles when Drs1 is depleted. Conversely, in wild-type cells, Nog2 normally associates with pre-ribosomes only after transcription is completed. The fact that we observed strong enrichment of Pol I subunits in pre-ribosomes purified using Nog2TAP suggests that upon depletion of Drs1, Nog2 now associates with pre-ribosomes cotranscriptionally. These data, plus our finding that Nog2 can associate with 35 S pre-rRNA upon depletion of Drs1, further strengthens our conclusion that 


\section{GAL-DRS1} Changes in Pol-I components

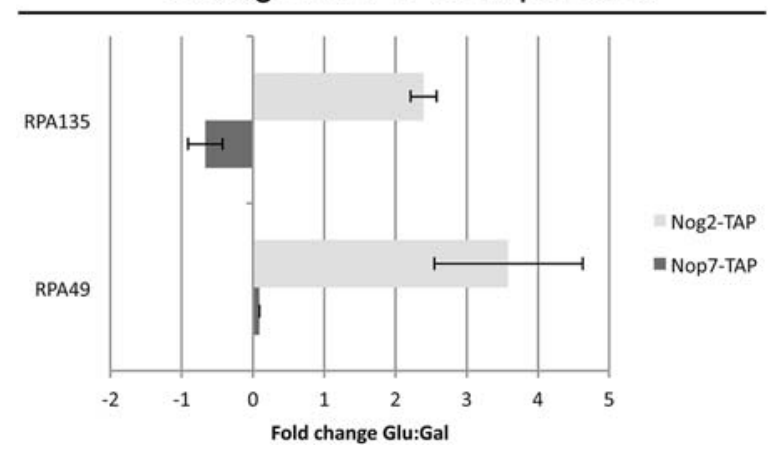

FIGURE 5. Nog2-containing pre-ribosomes are enriched with RNA polymerase I subunits upon depletion of Drs1. Pre-ribosomes were affinity-purified using either Nop7-TAP (dark gray bars) or Nog2-TAP (light gray bars) from the GAL-HA-DRS1 strain grown in YEPGal or shifted to YEPGlu to deplete Drs1. Purified pre-ribosomes were assayed by iTRAQ mass spectrometry as described in Figure 2A. Shown is the fold change in Pol I subunits identified. Error bars indicate the SEM.

depletion of Drs1, and subsequent disruption of ribosome assembly, causes a shift from co- to more post-transcriptional pre-rRNA processing. When this occurs, normally "late" associating assembly factors bind pre-ribosomes containing $35 \mathrm{~S}$ pre-rRNA and the Pol I machinery (Fig. 7).

\section{Co- vs. post-transcriptional pre-rRNA processing is dependent on cell growth rates and environmental stress}

Electron microscopy of actively transcribed rDNA revealed that when cells are rapidly dividing, a greater fraction of pre-rRNAs are processed cotranscriptionally (Osheim et al. 2004). However, when cells are grown to high density and cell proliferation slows, nascent transcripts are more frequently processed post-transcriptionally. Based on these previous observations, and because we only observed an accumulation of $35 \mathrm{~S}$ pre-rRNA after depletion of Drs1 for $16 \mathrm{~h}$, we hypothesized that the shift from co- to post-transcriptional pre-rRNA processing is not directly due to the absence of Drs1, but rather a decrease in cellular division rates upon disruption of ribosome biogenesis. Consistent with this idea, we did not observe an accumulation of 35 S pre-rRNA after a $4 \mathrm{~h}$ depletion of Drs1, when cells were still dividing at wild-type rates, even though the effect on $27 \mathrm{~S}$ pre-rRNA processing was clearly evident (Fig. 1B). Furthermore, we did not observe significant accumulation of high molecular weight proteins in pre-ribosomes purified using Nog2-TAP when Drs1 was depleted for $4 \mathrm{~h}$ compared to $16 \mathrm{~h}$ (Supplemental Fig. S5).

To more thoroughly investigate the relationship between cell division rates and pre-rRNA processing, we grew cells to increasing density until stationary phase and assayed pre-rRNA processing by Northern blotting. Generally, we observed decreased steady-state amounts of both prerRNAs and rRNAs as cells approached stationary phase, suggesting a global down-regulation in nascent ribosome production (Fig. 6A,B). It is likely that the decrease of $25 \mathrm{~S}$ and $18 \mathrm{~S}$ rRNAs is due to a combination of decreased ribosome production and dilution of preexisting ribosomes by cell division. Consistent with previous work from the Warner group, the decrease in pre-rRNAs occurred slightly prior to exit from exponential growth, suggesting that cells regulate ribosome synthesis according to their estimate for the potential for growth (Ju and Warner 1994).

Because $35 \mathrm{~S}$ pre-rRNA is produced in low amounts in rapidly dividing cells, and total cellular pre-rRNA/rRNA is decreased as cells approach stationary phase, it was difficult to detect $35 \mathrm{~S}$ pre-rRNA by Northern blotting. However, as cell division slowed, we observed a strong accumulation of $23 \mathrm{~S}$ pre-rRNA coincident with the decrease in $20 \mathrm{~S}$ prerRNA and $27 \mathrm{SA}_{2}$ pre-rRNA (Fig. $6 \mathrm{~B}$, lanes 4 and 5 , and $6 \mathrm{C})$. The $23 \mathrm{~S}$ pre-rRNA intermediate, extending from the $5^{\prime}$ end of the $35 \mathrm{~S}$ pre-rRNA to the $\mathrm{A}_{3}$ site, is generated by direct cleavage of the $\mathrm{A}_{3}$ site prior to cleavage at sites $\mathrm{A}_{0}, \mathrm{~A}_{1}$, and $\mathrm{A}_{2}$, and thus by definition is a marker for post-transcriptional pre-rRNA processing (Supplemental Fig. S3, bottom). $23 \mathrm{~S}$ pre-rRNA has been observed in a number of ribosome assembly mutants and had been suggested to be an aberrant intermediate. However, the $23 \mathrm{~S}$ intermediate that accumulates in many mutants when early steps of $60 \mathrm{~S}$ subunit assembly are blocked (including in the absence of Drs1, Fig. 1), can be processed to $18 \mathrm{~S}$ rRNA and serves as an alternative route for maturation of the small subunit when large subunit assembly is blocked (de la Cruz et al. 1998; Adams et al. 2002; Miles et al. 2005; Hierlmeier et al. 2012; Jakovljevic et al. 2012; Talkish et al. 2014).

To further test the relationship between cell growth rate and post-transcriptional pre-rRNA processing, we also assayed pre-rRNA processing when cells were grown under a variety of conditions previously shown to trigger an environmental stress response (Gasch et al. 2000). Northern blots were performed on RNA extracted from cells responding to heat-shock, cold-shock, low pH, dithiothreitol (DTT), rapamycin, and hydrogen peroxide. In all conditions except for cold-shock and treatment with $\mathrm{H}_{2} \mathrm{O}_{2}$, we observed a slight accumulation of $23 \mathrm{~S}$ pre-rRNA relative to $20 \mathrm{~S}$ pre-rRNA (Fig. $6 \mathrm{D})$. This was most evident when cells were treated with rapamycin, resulting in an observable accumulation of $35 \mathrm{~S}$ pre-rRNA as well.

Together, these results confirm previous observations that under conditions that cause cellular stress or decreased cell division rates, a greater fraction of pre-rRNAs are processed post-transcriptionally (Osheim et al. 2004). When this occurs, a greater fraction of the resulting $35 \mathrm{~S}$ pre-rRNA is cleaved directly at the $A_{3}$ site, prior to cleavage at the $A_{0}$, $A_{1}$, and $A_{2}$ sites (Supplemental Fig. S3). 
A

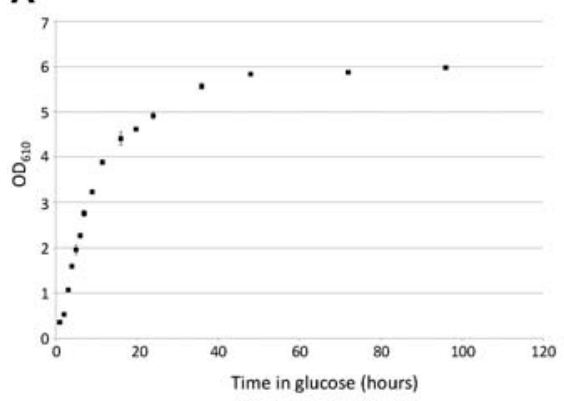

B

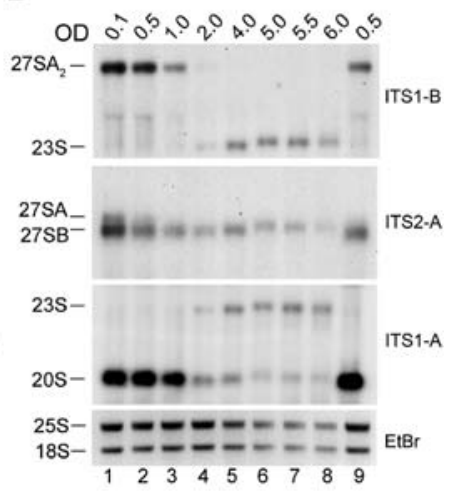

D
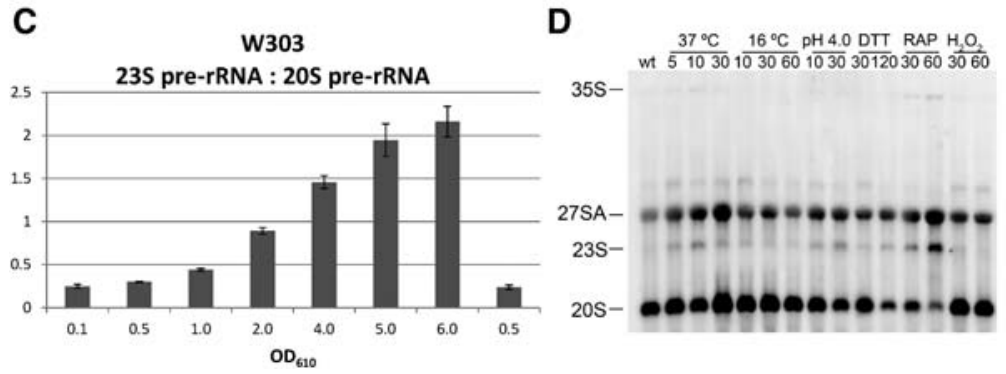

FIGURE 6. Pre-rRNA processing is dependent on cell growth. (A) The yeast strain W303 was grown in YEPGlu at $30^{\circ} \mathrm{C}$ from $\mathrm{OD}_{610}=0.1-6.0$. $(B)$ RNA was extracted from aliquots of the culture at the indicated $\mathrm{OD}_{610}$ and separated on a $1.2 \%$ agarose- $6 \%$ formaldehyde gel. Pre-rRNAs were assayed by Northern blotting with oligonucleotides indicated on the right. 25S rRNA and $18 \mathrm{~S}$ rRNA were visualized by ethidium bromide staining. Lane 9 represents cells grown to stationary phase, diluted to $\mathrm{OD}_{610}=0.01$, and then grown to $\mathrm{OD}_{610}=0.5$. $(C)$ The Northern blots described in $B$ were repeated in triplicate and the ratio of $23 \mathrm{~S}$ pre-rRNA to 20 S pre-rRNA was quantified. Error bars indicate the SEM. (D) To assay the effects of different cellular environments on pre-rRNA processing, the yeast strain W303 was grown in YEPGlu at $30^{\circ} \mathrm{C}$ to mid-log phase and then shifted to the indicated temperature or growth condition as described by Gasch et al. (2000) and Talkish et al. (2012). After the shift, whole-cell RNA was phenol extracted, separated on a $1.2 \%$ agarose- $6 \%$ formaldehyde gel, and pre-rRNAs were assayed by Northern blotting using a mixture of the oligonucleotides ITS1-A, ITS1-B, and ITS1-C.

\section{DISCUSSION}

In the course of studying the pre-60S subunit assembly factor Drs1, we observed a phenotype in which the global hierarchy of yeast ribosome assembly was changed. We do not think that this is specific to Drs1, but rather to decreased cellular growth upon disruption of ribosome assembly. Depletion of Drs1 resulted in the formation of early pre-ribosomal intermediates that contained unprocessed $35 \mathrm{~S}$ pre-rRNA as well as r-proteins and assembly factors previously thought to only bind to pre-ribosomes after a number of pre-rRNA processing steps have taken place. We believe that these results reflect a shift from largely cotranscriptional pre-rRNA processing to a greater fraction of post-transcriptional prerRNA processing based on the following: (i) Depletion of Drs1 initially blocks processing of $27 \mathrm{~S}$ pre-rRNAs; however, at later time-points when cell division decreases, there also is an accumulation of $35 \mathrm{~S}$ pre-rRNA, suggesting that prerRNAs are no longer cleaved at the $A_{0}, A_{1}$, or $A_{2}$ sites cotranscriptionally. (ii) The increased $35 \mathrm{~S}$ pre-rRNA that is produced upon depletion of Drs1 is packaged into early pre-ribosomes that contain both early-associating assembly factors and r-proteins, as well as assembly factors (Nog2, Arx1, and Lsg1) and rproteins (S3 and S20) that in wild-type cells associate with assembling subunits only after cleavage at the $\mathrm{A}_{2}$ site separates maturation of the pre-40S and pre-60S subunit intermediates. (iii) Consistent with coimmunoprecipitation of $35 \mathrm{~S}$ pre-rRNA with Nog2 when Drs1 is depleted, we observed that Nog2 copurifies increased amounts of Pol I subunits. These results suggest that pre-rRNA processing steps are in kinetic competition with the formation of protein binding sites. When pre-rRNAs are not cleaved cotranscriptionally, the binding sites for some normally late-associating factors can form during transcription, and lateassociating proteins can bind prior to completion of transcription and removal of spacer sequences.

The shift to a greater fraction of posttranscriptional pre-rRNA processing is likely due to decreased growth rates upon disruption of ribosome biogenesis, and not specific to the absence of Drs1. Growing cells to stationary phase or under environmental stress also results in decreased cotranscriptional cleavage at the $A_{0}, A_{1}$, and $A_{2}$ sites (Fig. 6; Osheim et al. 2004). Interestingly, under these conditions we also observe greater amounts of $23 \mathrm{~S}$ pre-rRNA, suggesting that nascent transcripts that are processed post-transcriptionally follow an alternative pre-rRNA processing pathway. This work raises novel ideas about ribosome assembly regarding the order and timing of pre-rRNA processing, the overall hierarchy of protein association with nascent pre-ribosomal particles, and the effects on pre-rRNA processing when early steps of assembly occur post-transcriptionally.

\section{Disruption of ribosome assembly results in increased post-transcriptional pre-rRNA processing}

Recent examination of pre-rRNA processing in yeast by electron microscopy of Miller chromatin spreads and rapid pulse-labeling approaches revealed that cleavage at the $A_{2}$ site (and presumably also the $\mathrm{A}_{0}$ and $\mathrm{A}_{1}$ sites) predominantly occurs cotranscriptionally (Osheim et al. 2004; Kos and Tollervey 2010). Cotranscriptional cleavage at the $\mathrm{A}_{2}$ site occurs $\sim 70 \%-80 \%$ of the time in rapidly dividing yeast cells. Thus, only $\sim 20 \%-30 \%$ of rRNA transcription results in a 
$35 \mathrm{~S}$ pre-rRNA that is processed posttranscriptionally in fast-growing wildtype cells. Furthermore, when yeast cells are grown to high density, the frequency of cotranscriptional $A_{0}, A_{1}$, and $A_{2}$ cleavage decreases dramatically, suggesting that cotranscriptional pre-rRNA processing is regulated by cell growth and division (Osheim et al. 2004). Consistent with these observations, it was recently shown that pre-rRNA in C. albicans is processed cotranscriptionally in rapidly dividing cells, but processed post-transcriptionally after cells undergo the diauxic shift (Pendrak and Roberts 2011).

Depletion of Drs1, as well as other proteins that function early in the biogenesis of $60 \mathrm{~S}$ ribosomal subunits, results in the accumulation $27 \mathrm{SA}_{3}$ pre-rRNA and a subsequent decrease in $27 \mathrm{SB}$ pre-rRNA (Fig. 1B; Sahasranaman et al. 2011). Interestingly, many of these early assembly mutants also exhibit increased $35 \mathrm{~S}$ pre-rRNA (Dunbar et al. 2000; Pestov et al. 2001; Adams et al. 2002; Oeffinger et al. 2002; Oeffinger and Tollervey 2003; Horsey et al. 2004; Miles et al. 2005). Often, the initial pre-rRNA processing phenotype is revealed early upon turning off expression of the protein of interest and before cell growth rates decrease, whereas the accumulation of $35 \mathrm{~S}$ pre-rRNA is revealed later, as cell division slows down. This later phenotype is often attributed to the sequestration of early-functioning assembly factors on stalled $66 \mathrm{~S}$ pre-ribosomes, causing early steps in pre-rRNA processing at the $A_{0}, A_{1}$, and $A_{2}$ sites to be affected, or as a quality control checkpoint (Venema and Tollervey 1999). However, a number of studies, including this one (Fig. 1D), have shown that pre-rRNAs are often turned over when ribosome assembly is blocked, particularly when early steps of $27 \mathrm{~S}$ pre-rRNA processing are impaired. Thus, it seems likely that many of the proteins in abortive intermediates are released during turnover to be reused for another round of assembly, and unlikely that the effects observed on $35 \mathrm{~S}$ pre-rRNA processing are only due to limited quantities of these proteins. Therefore, an equally plausible scenario is that disruption of early steps of ribosome biogenesis results in decreased cell growth and division, ultimately leading to a shift from cotranscriptional pre-rRNA processing to a greater fraction of post-transcriptional prerRNA processing (Figs. 1, 7). In fact, recent work from the Tollervey group revealed that disruption of the exonuclease

B

\section{co-transcriptional pre-rRNA processing}

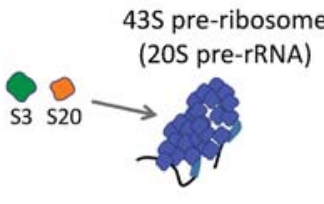

S pre-ribosome

$66 \mathrm{~S}$ pre-ribosome
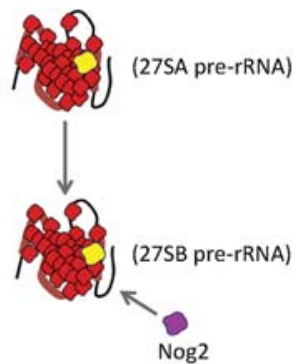

post-transcriptional pre-rRNA processing

Fepletion of Drs1 causes a shift from cotranscriptional pre-rRNA processing to postI (gray) and cleaved at the $\mathrm{A}_{2}$ site cotranscriptionally to first release a $43 \mathrm{~S}$ pre-ribosome conpre-rRNA (blue). As transcription continues, pre-rRNAs are bound cotranscriptionof Nog2 (purple). (B) Upon depletion of Drs1, pre-rRNAs are processed post-transcriptionally, richment of Pol I subunits with Nog2-TAP containing pre-ribosomes (Fig. 5) indicates that Nog2 associates with pre-ribosomes during transcription in the absence of Drs1.

Rat1, which functions in $27 \mathrm{SA}_{3}$ pre-rRNA processing, led to decreased cotranscriptional cleavage of nascent prerRNA transcripts (Axt et al. 2014).

\section{Co- vs. post-transcriptional pre-rRNA processing is linked to cell growth conditions}

The accumulation of $35 \mathrm{~S}$ pre-rRNA upon slowed cell growth that occurs in many different pre-60S subunit assembly mutants, and previous observations of cotranscriptional vs. post-transcriptional pre-rRNA processing by Miller chromatin spreads (Axt et al. 2014), suggest that the frequency of cotranscriptional pre-rRNA processing is linked to cell growth. Here we further investigate pre-rRNA processing 
by Northern blotting when cells are grown from exponential to stationary phase. As cell division slows, we observe decreased formation of $27 \mathrm{SA}_{2}$ and $20 \mathrm{~S}$ pre-rRNAs, consistent with decreased cotranscriptional cleavage at the $A_{0}, A_{1}$, and $\mathrm{A}_{2}$ sites. This is not simply due to a reduction in the synthesis of new ribosomes, as the levels of 27SB pre-rRNA and mature rRNAs did not change significantly at time-points where $27 \mathrm{SA}_{2}$ and $20 \mathrm{~S}$ pre-rRNAs were severely diminished (Fig. $6 \mathrm{~A}, \mathrm{~B}$, lane 4).

Interestingly, the decrease in $27 \mathrm{SA}_{2}$ and $20 \mathrm{~S}$ pre-rRNA levels as cells approached stationary phase is accompanied by an increase in $23 \mathrm{~S}$ pre-rRNA. This is also observed upon shifting yeast cells from ideal growth conditions to stressful conditions (Fig. 6D). $23 \mathrm{~S}$ pre-rRNA is produced by direct cleavage of the $A_{3}$ site in ITS1, prior to cleavage at sites $A_{0}, A_{1}$, and $A_{2}$, and thus by definition is derived post-transcriptionally. There is much debate about whether $23 \mathrm{~S}$ pre-rRNA is a genuine or aberrant pre-rRNA processing intermediate. However, recent studies, including this one (Fig. 1), have shown that $23 \mathrm{~S}$ pre-rRNA is likely an alternative, on-pathway intermediate to mature 18S rRNA (de la Cruz et al. 1998; Adams et al. 2002; Miles et al. 2005; Hierlmeier et al. 2012; Jakovljevic et al. 2012; Talkish et al. 2014). Depletion of Drs1, like many pre-60S subunit assembly factors that function during processing of $27 \mathrm{~S}$ pre-rRNA, results in a dramatic decrease in $20 \mathrm{~S}$ pre-rRNA with a corresponding increase in $35 \mathrm{~S}$ and $23 \mathrm{~S}$ pre-rRNA levels (Fig. 1). However, $18 \mathrm{~S}$ rRNA is still produced at wild-type levels, indicating that maturation of pre-40S subunits can occur through the $23 \mathrm{~S}$ pre-rRNA intermediate. Consistent with this, it was recently shown in Arabidopsis that early processing steps in the $5^{\prime}$ external transcribed spacer sequence can be bypassed and still result in normal levels of mature rRNAs (Weis et al. 2015).

Together, the above results with pre-60S subunit assembly factor mutants show that as cell growth decreases, so does the frequency of cotranscriptional separation of pre-40S and pre-60S subunit assembly intermediates. Furthermore, a greater fraction of post-transcriptionally processed prerRNAs are cleaved directly at the $\mathrm{A}_{3}$ site to produce $23 \mathrm{~S}$ pre-rRNA, serving as an alternative intermediate to mature $18 \mathrm{~S}$ rRNA. This suggests that there are fundamental differences in the assembly of nascent particles when pre-rRNAs are processed post-transcriptionally vs. cotranscriptionally. However, the assembly events that dictate co- vs. post-transcriptional processing, and how they are related to cell growth rates, are still unknown.

\section{Transcription and assembly}

Why might pre-rRNAs be processed differently cotranscriptionally vs. post-transcriptionally? One possibility is that changes in cell growth rates lead to changes in RNA polymerase I activity, ultimately leading to different RNA folding and assembly pathways. Work from Schneider and colleagues re- vealed that there is indeed a relationship between Pol I transcription rates and pre-rRNA processing (Schneider et al. 2007). Mutations in Pol I that slow elongation resulted in a number of pre-rRNA processing defects, including accumulation of post-transcriptionally derived $23 \mathrm{~S}$ pre-rRNA. Furthermore, rRNA is transcribed from tandemly repeated rDNA genes, each of which is occupied by upwards of 120 Pol I molecules (Osheim et al. 2004; Viktorovskaya and Schneider 2015). However, variation in the density of Pol I molecules along the transcript suggests polymerase pausing (El Hage et al. 2010; Turowski and Tollervey 2015). Chromatin-immunoprecipitation studies revealed that Pol I occupancy was highest over the $5^{\prime}$ external transcribed spacer, but also revealed a peak of occupancy across ITS1, near the $A_{2}$ and $A_{3}$ sites (El Hage et al. 2010). Thus, an interesting possibility is that high rates of transcription in rapidly dividing yeast leads to a pile-up or pausing of Pol I over ITS1. This may allow ITS1 to fold in a way that promotes cotranscriptional cleavage of ITS1 at the $\mathrm{A}_{2}$ site. Alternatively, in slowly dividing cells where there is less of a demand for the synthesis of new ribosomes, decreased Pol I occupancy might lead to differences in transcription rates. This may cause ITS1 to fold in a way that either inhibits cotranscriptional cleavage at the $A_{0}, A_{1}$, and $A_{2}$ sites or promotes post-transcriptional processing at the $\mathrm{A}_{3}$ site.

The occupancy and activity of Pol I might also influence the way other regions of the rRNA fold, leading to the formation of late-protein binding sites before any pre-rRNA processing steps occur. Our results show that disruption of ribosome assembly upon depletion of Drs1 results in the formation of an intermediate that contains unprocessed 35S pre-rRNA associated with assembly factors (Nog2, Arx1, and Lsg1) and r-proteins (S3 and S20) previously only thought to bind post-transcriptionally. Furthermore, mass spectrometric analysis of these particles revealed that Nog2 can associate cotranscriptionally when pre-rRNAs are processed post-transcriptionally. Together, these results suggest there is a kinetic foot-race between the processing of prerRNAs and the folding and formation of assembly factor and $r$-protein binding sites.

\section{MATERIALS AND METHODS}

\section{Construction and growth of yeast strains}

Yeast strains used in this study are listed in Supplemental Table S1. Unless otherwise noted, yeast were grown at $30^{\circ} \mathrm{C}$ in YEPGlu $(2 \%$ dextrose, $2 \%$ peptone, and $1 \%$ yeast extract) or YEPGal (2\% galactose, $2 \%$ peptone, and $1 \%$ yeast extract). Cells were harvested at mid-log phase, at 3-5 $\times 10^{7}$ cells $/ \mathrm{mL}$, unless otherwise indicated.

To assay pre-rRNA processing when cells are grown under different environmental stressors, the yeast strain W303 was used. Cells were grown to mid-log phase in YEPGlu at $30^{\circ} \mathrm{C}$ and then shifted for the indicated time to either $16^{\circ} \mathrm{C}$ or $37^{\circ} \mathrm{C}$, low $\mathrm{pH}(4.0)$, or media supplemented with dithiothreitol (DTT, $2.5 \mathrm{mM}$ ), rapamycin (RAP, $200 \mathrm{ng} / \mathrm{mL}$ ), or hydrogen peroxide $\left(\mathrm{H}_{2} \mathrm{O}_{2} ; 0.3 \mathrm{mM}\right)$. After 
treatment, cells were harvested by centrifugation, flash-frozen, and RNA was extracted for Northern blotting.

Yeast strains conditional for expression of Drs1 were constructed as previously described (Longtine et al. 1998). Briefly, sequences containing the selectable marker TRP1, plus the GAL1 promoter followed by an ATG initiator codon and sequences encoding three copies of the hemaglutinin (3HA) epitope were amplified by PCR. The PCR products were transformed into yeast and transformants were screened for correct integration of the GAL1 promoter and 3HA tag by Western blotting with anti-HA antisera. Strains containing the GAL1 promoter fused with the DRS1 ORF were grown at $30^{\circ} \mathrm{C}$ in YEPGal to $3-5 \times 10^{7}$ cells $/ \mathrm{mL}$, or were grown in YEPGal and then shifted to YEPGlu for indicated times, to $3-5 \times 10^{7}$ cells/mL, to deplete Drs1 in vivo.

Yeast strains expressing C-terminal TAP-tagged proteins or C-terminal 3HA-tagged proteins were created by PCR of the tag sequences and a selectable marker (URA3 for the TAP tag and HIS3 or kanMX6 for the 3HA tag), transformation, and selection as described in Rigaut et al. (1999) or Longtine et al. (1998), respectively.

\section{Assaying pre-rRNA processing and turnover}

Steady-state levels of pre-rRNAs and rRNAs were assayed by Northern blotting and primer extension, and synthesis and turnover of pre-rRNAs were monitored by pulse-chase assays, as previously described (Horsey et al. 2004; Jakovljevic et al. 2012), with the following modifications. Prior to loading on gels, RNA was quantified using a Nano Drop 2000C spectrophotometer (Thermo Fisher Scientific). Five micrograms of RNA was used for Northern blotting and primer extension. Sequences of oligonucleotides used for primer extension and Northern blotting are available upon request. The radioactive signal in bands on Northern blots was quantified using ImageJ.

For pulse-chase assays, cells were pulse labeled with [ ${ }^{3} \mathrm{H}$ methyl]methionine for $5 \mathrm{~min}$ and chased with a molar excess of unlabeled methionine for 2, 5, 10, and $60 \mathrm{~min}$. Total RNA was extracted and equal counts per min of each sample was loaded and separated on a $1.2 \%$ agarose- $6 \%$ formaldehyde gel. RNA was transferred to a nitrocellulose membrane (Bio-Rad) and was detected by exposure to Biomax MS film (Carestream).

\section{Affinity purification of pre-ribosomes}

Ribosome assembly intermediates were affinity-purified from whole-cell extracts using magnetic Dynabeads (Invitrogen) as described in Sahasranaman et al. (2011). RNA enriched in these purified pre-ribosomes was extracted, as described in Sahasranaman et al. (2011), and was assayed by primer extension as described in Horsey et al. (2004).

\section{Protein extraction, SDS-PAGE, and Western blot analysis}

Proteins in whole cell extracts were prepared for gel electrophoresis as previously described in Ausubel et al. (1994). Proteins were isolated from affinity-purified pre-ribosomes by precipitation with $10 \%$ TCA, and were resuspended in SDS sample buffer. Proteins were resolved by SDS-PAGE on 4\%-20\% Tris-Glycine Novex precast gels (Invitrogen), and stained with silver by standard methods.
Proteins from whole-cell extracts or from purified pre-ribosomes were assayed by Western blot analysis with the following modifications. To enable detection of multiple different proteins on the same blot, after electroblotting, nitrocellulose membranes were cut into smaller pieces based on previously established mobility of different proteins. Each section of membrane was then probed with the appropriate antibody and developed. TAP-tagged proteins were detected using alkaline phosphatase conjugated to IgG (Pierce). HAtagged proteins were identified with mouse monoclonal antibody 12CA5. Myc-tagged proteins were identified with mouse monoclonal antibody 9e10 (Developmental Studies Hybridoma Bank). Otherwise, antibodies specific for r-proteins or ribosomal assembly factors were used. To assay Nog2 protein by Western blotting, NuPage 4\%-12\% Bis-Tris gels (Invitrogen) were used, since Nog2 comigrates with IgG on 4\%-20\% Novex gels. AP-conjugated antimouse or anti-rabbit secondary antibodies (Promega) were used, and colorimetric detection was performed using NBT and BCIP (Promega) to visualize the signal.

\section{Affinity purification of pre-ribosomes and analysis by iTRAQ mass spectrometry}

For semiquantitative iTRAQ mass spectrometry, pre-ribosomes were purified as described above. Pre-ribosomes were purified from $1 \mathrm{~L}$ of cell culture at $3-5 \times 10^{7}$ cells $/ \mathrm{mL}$. Purified pre-ribosomes were eluted from the IgG Dynabeads, precipitated with $10 \%$ TCA, and resuspended in $20 \mu \mathrm{L}$ of $20 \mathrm{mM}$ HEPES $\mathrm{pH}$ 7.4. iTRAQ labeling and quantification were performed as previously described in Jiang et al. (2007).

\section{PyMOL}

PyMOL images of the structure of yeast 60S and 40S ribosomal subunits were generated using PDB file 4V88 (Ben-Shem et al. 2011).

\section{SUPPLEMENTAL MATERIAL}

Supplemental material is available for this article.

\section{ACKNOWLEDGMENTS}

We are grateful to the following people for generously providing antibodies: Michael McAlear (Ebp2), Jesus de la Cruz and Patrick Linder (Has1), David Goldfarb (Nip7), Elizabeth Tosta (Cic1), Cosmin Saveanu and Micheline Fromont-Racine (Rlp24, Nsa2, Tif6, and Nog2), Arlen Johnson (rpL8), K. Siegers (rpL25), and Sabine Rospert (rpL17). This work was supported by National Institutes of Health grant GM28301 (J.L.W.), National Institutes of Health grant 1R01GM077628 (J.R.M.), funds from the David Scaife Family Charitable Foundation (award 141RA01; J.L.W., J.J., and J.T.), the Richard King Mellon Foundation Presidential Graduate Fellowship in the Life Sciences (J.T.), the Semon H. Stupakoff Scholarship (J.T.), and the Roche/ARCS Foundation Scholar Award (S.B.).

Received December 22, 2015; accepted February 18, 2016. 


\section{REFERENCES}

Adams CC, Jakovljevic J, Roman J, Harnpicharnchai P, Woolford JL Jr. 2002. Saccharomyces cerevisiae nucleolar protein Nop7p is necessary for biogenesis of 60S ribosomal subunits. RNA 8: 150-165.

Adilakshmi T, Bellur DL, Woodson SA. 2008. Concurrent nucleation of $16 \mathrm{~S}$ folding and induced fit in $30 \mathrm{~S}$ ribosome assembly. Nature 455: $1268-1272$.

Ausubel FM, Brent R, Kingston RE, Moore DD, Seidman JG, Smith JA, Struhl K. 1994. Current protocols in molecular biology. Wiley, New York.

Axt K, French SL, Beyer AL, Tollervey D. 2014. Kinetic analysis demonstrates a requirement for the Rat 1 exonuclease in cotranscriptional pre-rRNA cleavage. PLoS One 9: e85703.

Basu U, Si K, Warner JR, Maitra U. 2001. The Saccharomyces cerevisiae TIF6 gene encoding translation initiation factor 6 is required for $60 \mathrm{~S}$ ribosomal subunit biogenesis. Mol Cell Biol 21: 1453-1462.

Ben-Shem A, Garreau de Loubresse N, Melnikov S, Jenner L, Yusupova G, Yusupov M. 2011. The structure of the eukaryotic ribosome at 3.0 A resolution. Science 334: 1524-1529.

Bradatsch B, Katahira J, Kowalinski E, Bange G, Yao W, Sekimoto T, Baumgartel V, Boese G, Bassler J, Wild K, et al. 2007. Arx1 functions as an unorthodox nuclear export receptor for the 605 preribosomal subunit. Mol Cell 27: 767-779.

Bradatsch B, Leidig C, Granneman S, Gnadig M, Tollervey D, Bottcher B, Beckmann R, Hurt E. 2012. Structure of the pre-60S ribosomal subunit with nuclear export factor Arxl bound at the exit tunnel. Nat Struct Mol Biol 19: 1234-1241.

Burger F, Daugeron MC, Linder P. 2000. Dbp10p, a putative RNA helicase from Saccharomyces cerevisiae, is required for ribosome biogenesis. Nucleic Acids Res 28: 2315-2323.

Culver GM. 2003. Assembly of the 30 S ribosomal subunit. Biopolymers 68: $234-249$.

Daugeron MC, Kressler D, Linder P. 2001. Dbp9p, a putative ATP-dependent RNA helicase involved in 60S-ribosomal-subunit biogenesis, functionally interacts with Dbp6p. RNA 7: 1317-1334.

de la Cruz J, Kressler D, Rojo M, Tollervey D, Linder P. 1998. Spb4p, an essential putative RNA helicase, is required for a late step in the assembly of 60 S ribosomal subunits in Saccharomyces cerevisiae. RNA 4: $1268-1281$.

de la Cruz J, Sanz-Martinez E, Remacha M. 2005. The essential WD-repeat protein Rsa4p is required for rRNA processing and intra-nuclear transport of 60S ribosomal subunits. Nucleic Acids Res 33: 5728-5739.

Dembowski JA, Kuo B, Woolford JL Jr. 2013. Has1 regulates consecutive maturation and processing steps for assembly of $60 \mathrm{~S}$ ribosomal subunits. Nucleic Acids Res 41: 7889-7904.

Dez C, Froment C, Noaillac-Depeyre J, Monsarrat B, CaizerguesFerrer M, Henry Y. 2004. Npalp, a component of very early pre$60 S$ ribosomal particles, associates with a subset of small nucleolar RNPs required for peptidyl transferase center modification. Mol Cell Biol 24: 6324-6337.

Dunbar DA, Dragon F, Lee SJ, Baserga SJ. 2000. A nucleolar protein related to ribosomal protein L7 is required for an early step in large ribosomal subunit biogenesis. Proc Natl Acad Sci 97: 13027-13032.

El Hage A, French SL, Beyer AL, Tollervey D. 2010. Loss of Topoisomerase I leads to R-loop-mediated transcriptional blocks during ribosomal RNA synthesis. Genes Dev 24: 1546-1558.

Emery B, de la Cruz J, Rocak S, Deloche O, Linder P. 2004. Has1p, a member of the DEAD-box family, is required for $40 \mathrm{~S}$ ribosomal subunit biogenesis in Saccharomyces cerevisiae. Mol Microbiol 52: $141-158$

Fatica A, Cronshaw AD, Dlakic M, Tollervey D. 2002. Ssf1p prevents premature processing of an early pre-60S ribosomal particle. Mol Cell 9: 341-351.

Fatica A, Oeffinger M, Dlakic M, Tollervey D. 2003. Noblp is required for cleavage of the $3^{\prime}$ end of 18S rRNA. Mol Cell Biol 23: $1798-1807$.
Fernandez-Pevida A, Kressler D, de la Cruz J. 2014. Processing of preribosomal RNA in Saccharomyces cerevisiae. Wiley Interdiscip Rev RNA 6: 191-209.

Ferreira-Cerca S, Poll G, Kuhn H, Neueder A, Jakob S, Tschochner H, Milkereit P. 2007. Analysis of the in vivo assembly pathway of eukaryotic 40S ribosomal proteins. Mol Cell 28: 446-457.

Galani K, Nissan TA, Petfalski E, Tollervey D, Hurt E. 2004. Rea1, a dynein-related nuclear AAA-ATPase, is involved in late rRNA processing and nuclear export of $60 \mathrm{~S}$ subunits. J Biol Chem 279: 55411-55418.

Gamalinda M, Ohmayer U, Jakovljevic J, Kumcuoglu B, Woolford J, Mbom B, Lin L, Woolford JL Jr. 2014. A hierarchical model for assembly of eukaryotic 60 S ribosomal subunit domains. Genes Dev 28: 198-210.

Gasch AP, Spellman PT, Kao CM, Carmel-Harel O, Eisen MB, Storz G, Botstein D, Brown PO. 2000. Genomic expression programs in the response of yeast cells to environmental changes. Mol Biol Cell 11: 4241-4257.

Held WA, Mizushima S, Nomura M. 1973. Reconstitution of Escherichia coli $30 \mathrm{~S}$ ribosomal subunits from purified molecular components. J Biol Chem 248: 5720-5730.

Hierlmeier T, Merl J, Sauert M, Perez-Fernandez J, Schultz P, Bruckmann A, Hamperl S, Ohmayer U, Rachel R, Jacob A, et al. 2012. Rrp5p, Noc1p and Noc2p form a protein module which is part of early large ribosomal subunit precursors in S. cerevisiae. Nucleic Acids Res 41: 1191-1210.

Horsey EW, Jakovljevic J, Miles TD, Harnpicharnchai P, Woolford JL Jr. 2004. Role of the yeast Rrp1 protein in the dynamics of pre-ribosome maturation. RNA 10: 813-827.

Jakovljevic J, Gamalinda M, Talkish J, Alexander L, Linneman J, Milkereit P, Woolford JL Jr. 2012. Ribosomal proteins L7 and L8 function in concert with six A3 assembly factors to propagate assembly of domain I of $25 \mathrm{~S}$ rRNA in yeast $60 \mathrm{~S}$ ribosomal subunits. RNA 18: $1805-1822$.

Jiang M, Sullivan SM, Walker AK, Strahler JR, Andrews PC, Maddock JR. 2007. Identification of novel Escherichia coli ribosome-associated proteins using isobaric tags and multidimensional protein identification techniques. J Bacteriol 189: 3434-3444.

Ju Q, Warner JR. 1994. Ribosome synthesis during the growth cycle of Saccharomyces cerevisiae. Yeast 10: 151-157.

Kallstrom G, Hedges J, Johnson A. 2003. The putative GTPases Nog1p and Lsg1p are required for $60 \mathrm{~S}$ ribosomal subunit biogenesis and are localized to the nucleus and cytoplasm, respectively. Mol Cell Biol 23: 4344-4355.

Karbstein K. 2011. Inside the 40 S ribosome assembly machinery. Curr Opin Chem Biol 15: 657-663.

Kos M, Tollervey D. 2010. Yeast pre-rRNA processing and modification occur cotranscriptionally. Mol Cell 37: 809-820.

Kressler D, de la Cruz J, Rojo M, Linder P. 1998. Dbp6p is an essential putative ATP-dependent RNA helicase required for 60S-ribosomalsubunit assembly in Saccharomyces cerevisiae. Mol Cell Biol 18: $1855-1865$.

Kressler D, Rojo M, Linder P, Cruz J. 1999. Spb1p is a putative methyltransferase required for $60 \mathrm{~S}$ ribosomal subunit biogenesis in Saccharomyces cerevisiae. Nucleic Acids Res 27: 4598-4608.

Kressler D, Roser D, Pertschy B, Hurt E. 2008. The AAA ATPase Rix7 powers progression of ribosome biogenesis by stripping Nsal from pre-60S particles. J Cell Biol 181: 935-944.

Lebreton A, Rousselle JC, Lenormand P, Namane A, Jacquier A, Fromont-Racine M, Saveanu C. 2008. 60S ribosomal subunit assembly dynamics defined by semi-quantitative mass spectrometry of purified complexes. Nucleic Acids Res 36: 4988-4999.

Longtine MS, McKenzie A III, Demarini DJ, Shah NG, Wach A, Brachat A, Philippsen P, Pringle JR. 1998. Additional modules for versatile and economical PCR-based gene deletion and modification in Saccharomyces cerevisiae. Yeast 14: 953-961.

Matsuo Y, Granneman S, Thoms M, Manikas RG, Tollervey D, Hurt E. 2014. Coupled GTPase and remodelling ATPase activities form a checkpoint for ribosome export. Nature 505: 112-116. 
Merl J, Jakob S, Ridinger K, Hierlmeier T, Deutzmann R, Milkereit P, Tschochner H. 2010. Analysis of ribosome biogenesis factor-modules in yeast cells depleted from pre-ribosomes. Nucleic Acids Res 38: $3068-3080$.

Miles TD, Jakovljevic J, Horsey EW, Harnpicharnchai P, Tang L, Woolford JL Jr. 2005. Ytm1, Nop7, and Erb1 form a complex necessary for maturation of yeast $66 \mathrm{~S}$ preribosomes. Mol Cell Biol 25: 10419-10432.

Mougey EB, O’Reilly M, Osheim Y, Miller OL Jr, Beyer A, SollnerWebb B. 1993. The terminal balls characteristic of eukaryotic rRNA transcription units in chromatin spreads are rRNA processing complexes. Genes Dev 7: 1609-1619.

Mulder AM, Yoshioka C, Beck AH, Bunner AE, Milligan RA, Potter CS, Carragher B, Williamson JR. 2010. Visualizing ribosome biogenesis: parallel assembly pathways for the 30 S subunit. Science 330: 673 677.

Nierhaus KH, Dohme F. 1974. Total reconstitution of functionally active 50S ribosomal subunits from Escherichia coli. Proc Natl Acad Sci 71: 4713-4717.

Nissan TA, Bassler J, Petfalski E, Tollervey D, Hurt E. 2002. 60S pre-ribosome formation viewed from assembly in the nucleolus until export to the cytoplasm. EMBO J 21: 5539-5547.

Oeffinger M, Tollervey D. 2003. Yeast Nop15p is an RNA-binding protein required for pre-rRNA processing and cytokinesis. EMBO J 22: 6573-6583.

Oeffinger M, Leung A, Lamond A, Tollervey D. 2002. Yeast Pescadillo is required for multiple activities during $60 \mathrm{~S}$ ribosomal subunit synthesis. RNA 8: 626-636.

Osheim YN, French SL, Keck KM, Champion EA, Spasov K, Dragon F, Baserga SJ, Beyer AL. 2004. Pre-18S ribosomal RNA is structurally compacted into the SSU processome prior to being cleaved from nascent transcripts in Saccharomyces cerevisiae. Mol Cell 16: 943-954.

Pendrak ML, Roberts DD. 2011. Ribosomal RNA processing in Candida albicans. RNA 17: 2235-2248.

Pestov DG, Stockelman MG, Strezoska Z, Lau LF. 2001. ERB1, the yeast homolog of mammalian Bop1, is an essential gene required for maturation of the $25 \mathrm{~S}$ and $5.8 \mathrm{~S}$ ribosomal RNAs. Nucleic Acids Res 29: $3621-3630$

Rigaut G, Shevchenko A, Rutz B, Wilm M, Mann M, Seraphin B. 1999. A generic protein purification method for protein complex characterization and proteome exploration. Nat Biotechnol 17: 1030-1032.

Ripmaster TL, Vaughn GP, Woolford JL Jr. 1992. A putative ATP-dependent RNA helicase involved in Saccharomyces cerevisiae ribosome assembly. Proc Natl Acad Sci 89: 11131-11135.

Rodriguez-Mateos M, Garcia-Gomez JJ, Francisco-Velilla R, Remacha M, de la Cruz J, Ballesta JP. 2009. Role and dynamics of the ribosomal protein $\mathrm{P} 0$ and its related trans-acting factor Mrt4 during ribosome assembly in Saccharomyces cerevisiae. Nucleic Acids Res 37: 7519-7532.

Sahasranaman A, Dembowski J, Strahler J, Andrews P, Maddock J, Woolford JL Jr. 2011. Assembly of Saccharomyces cerevisiae 60S ribosomal subunits: role of factors required for $27 \mathrm{~S}$ pre-rRNA processing. EMBO J 30: 4020-4032.

Saveanu C, Bienvenu D, Namane A, Gleizes PE, Gas N, Jacquier A, Fromont-Racine M. 2001. Nog2p, a putative GTPase associated with pre-60S subunits and required for late $60 \mathrm{~S}$ maturation steps. EMBO J 20: 6475-6484.

Saveanu C, Namane A, Gleizes PE, Lebreton A, Rousselle JC, NoaillacDepeyre J, Gas N, Jacquier A, Fromont-Racine M. 2003. Sequential protein association with nascent $60 \mathrm{~S}$ ribosomal particles. Mol Cell Biol 23: 4449-4460.
Saveanu C, Rousselle JC, Lenormand P, Namane A, Jacquier A, Fromont-Racine M. 2007. The p21-activated protein kinase inhibitor Skb15 and its budding yeast homologue are 60S ribosome assembly factors. Mol Cell Biol 27: 2897-2909.

Schafer T, Strauss D, Petfalski E, Tollervey D, Hurt E. 2003. The path from nucleolar $90 \mathrm{~S}$ to cytoplasmic $40 \mathrm{~S}$ pre-ribosomes. EMBO J 22: $1370-1380$.

Schneider DA, Michel A, Sikes ML, Vu L, Dodd JA, Salgia S, Osheim YN, Beyer AL, Nomura M. 2007. Transcription elongation by RNA polymerase I is linked to efficient rRNA processing and ribosome assembly. Mol Cell 26: 217-229.

Shimoji K, Jakovljevic J, Tsuchihashi K, Umeki Y, Wan K, Kawasaki S, Talkish J, Woolford JL Jr, Mizuta K. 2012. Ebp2 and Brx1 function cooperatively in 60S ribosomal subunit assembly in Saccharomyces cerevisiae. Nucleic Acids Res 40: 4574-4588.

Strunk BS, Karbstein K. 2009. Powering through ribosome assembly. RNA 15: 2083-2104.

Strunk BS, Loucks CR, Su M, Vashisth H, Cheng S, Schilling J, Brooks CL III, Karbstein K, Skiniotis G. 2011. Ribosome assembly factors prevent premature translation initiation by $40 \mathrm{~S}$ assembly intermediates. Science 333: 1449-1453.

Sun C, Woolford JL Jr. 1994. The yeast NOP4 gene product is an essential nucleolar protein required for pre-rRNA processing and accumulation of 60 S ribosomal subunits. EMBO J 13: 3127-3135.

Sykes MT, Williamson JR. 2009. A complex assembly landscape for the 30 S ribosomal subunit. Annu Rev Biophys 38: 197-215.

Talkington MW, Siuzdak G, Williamson JR. 2005. An assembly landscape for the 30S ribosomal subunit. Nature 438: 628-632.

Talkish J, Zhang J, Jakovljevic J, Horsey EW, Woolford JL Jr. 2012. Hierarchical recruitment into nascent ribosomes of assembly factors required for 27SB pre-rRNA processing in Saccharomyces cerevisiae. Nucleic Acids Res 40: 8646-8661.

Talkish J, Campbell IW, Sahasranaman A, Jakovljevic J, Woolford JL Jr. 2014. Ribosome assembly factors Pwp1 and Nop12 are important for folding of 5.8S rRNA during ribosome biogenesis in Saccharomyces cerevisiae. Mol Cell Biol 34: 1863-1877.

Turowski TW, Tollervey D. 2015. Cotranscriptional events in eukaryotic ribosome synthesis. Wiley Interdiscip Rev RNA 6: 129-139.

Venema J, Tollervey D. 1999. Ribosome synthesis in Saccharomyces cerevisiae. Annu Rev Genet 33: 261-311.

Viktorovskaya OV, Schneider DA. 2015. Functional divergence of eukaryotic RNA polymerases: unique properties of RNA polymerase I suit its cellular role. Gene 556: 19-26.

Wehner KA, Baserga SJ. 2002. The $\sigma^{70}$-like motif: a eukaryotic RNA binding domain unique to a superfamily of proteins required for ribosome biogenesis. Mol Cell 9: 329-339.

Weis BL, Palm D, Missbach S, Bohnsack MT, Schleiff E. 2015. atBRX1-1 and atBRX1-2 are involved in an alternative rRNA processing pathway in Arabidopsis thaliana. RNA 21: 415-425.

Woolford JL Jr, Baserga SJ. 2013. Ribosome biogenesis in the yeast Saccharomyces cerevisiae. Genetics 195: 643-681.

Zanchin NI, Goldfarb DS. 1999. Nip7p interacts with Nop8p, an essential nucleolar protein required for $60 \mathrm{~S}$ ribosome biogenesis, and the exosome subunit Rrp43p. Mol Cell Biol 19: 1518-1525.

Zanchin NI, Roberts P, DeSilva A, Sherman F, Goldfarb DS. 1997. Saccharomyces cerevisiae Nip7p is required for efficient 60S ribosome subunit biogenesis. Mol Cell Biol 17: 5001-5015.

Zhang J, Harnpicharnchai P, Jakovljevic J, Tang L, Guo Y, Oeffinger M, Rout MP, Hiley SL, Hughes T, Woolford JL Jr. 2007. Assembly factors Rpf 2 and Rrs 1 recruit 5S rRNA and ribosomal proteins rpL5 and rpL11 into nascent ribosomes. Genes Dev 21: 2580-2592. 

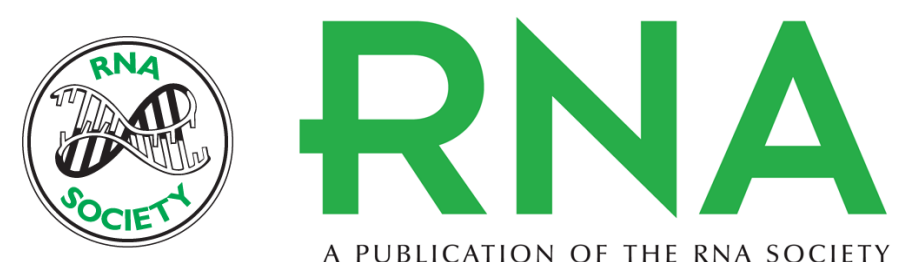

A PUBLICATION OF THE RNA SOCIETY

\section{Disruption of ribosome assembly in yeast blocks cotranscriptional pre-rRNA processing and affects the global hierarchy of ribosome biogenesis}

Jason Talkish, Stephanie Biedka, Jelena Jakovljevic, et al.

RNA 2016 22: 852-866 originally published online April 1, 2016

Access the most recent version at doi:10.1261/rna.055780.115

Supplemental Material

References

Creative Commons License

Email Alerting Service
http://rnajournal.cshlp.org/content/suppl/2016/04/01/rna.055780.115.DC1

This article cites 76 articles, 41 of which can be accessed free at: http://rnajournal.cshlp.org/content/22/6/852.full.html\#ref-list-1

This article is distributed exclusively by the RNA Society for the first 12 months after the full-issue publication date (see http://rnajournal.cshlp.org/site/misc/terms.xhtml). After 12 months, it is available under a Creative Commons License (Attribution-NonCommercial 4.0 International), as described at http://creativecommons.org/licenses/by-nc/4.0/.

Receive free email alerts when new articles cite this article - sign up in the box at the top right corner of the article or click here.

To subscribe to RNA go to:

http://rnajournal.cshlp.org/subscriptions 